\title{
Distinct Mechanisms Produce Functionally Complementary Actions of Neuropeptides That Are Structurally Related But Derived from Different Precursors
}

\author{
Ferdinand S. Vilim, ${ }_{1}^{1}$ Kosei Sasaki, ${ }^{1}$ Jurgen Rybak, ${ }^{2}$ Vera Alexeeva, ${ }^{1}$ Elizabeth C. Cropper, ${ }^{1}$ Jian Jing, ${ }^{1}$ Irina V. Orekhova, ${ }^{1}$ \\ Vladimir Brezina, ${ }^{1}$ David Price, ${ }^{3}$ Elena V. Romanova, ${ }^{4}$ Stanislav S. Rubakhin, ${ }^{4}$ Nathan Hatcher, ${ }^{4}$ Jonathan V. Sweedler, ${ }^{4}$ \\ and Klaudiusz R. Weiss ${ }^{1}$ \\ ${ }^{1}$ Department of Neuroscience, Mount Sinai School of Medicine, New York, New York 10029, ${ }^{2}$ Department of Biologie-Neurobiologie, Free University of \\ Berlin, 14195 Berlin, Germany, ${ }^{3}$ Whitney Laboratory for Marine Bioscience, University of Florida, St. Augustine, Florida 32080, and ${ }^{4}$ Department of \\ Chemistry and Beckman Institute, University of Illinois, Urbana, Illinois 61801
}

\begin{abstract}
Many bioactive neuropeptides containing RFamide at their $\mathrm{C}$ terminus have been described in both invertebrates and vertebrates. To obtain insight into the functional logic of RFamide signaling, we investigate it here in the feeding system of Aplysia. We focus on the expression, localization, and actions of two families of RFamide peptides, the FRFamides and FMRFamide, in the central neuronal circuitry and the peripheral musculature that generate the feeding movements. We describe the cloning of the FRFamide precursor protein and show that the FRFamides and FMRFamide are derived from different precursors. We map the expression of the FRFamide and FMRFamide precursors in the feeding circuitry using in situ hybridization and immunostaining and confirm proteolytic processing of the FRFamide precursor by mass spectrometry. We show that the two precursors are expressed in different populations of sensory neurons in the feeding system. In a representative feeding muscle, we demonstrate the presence of both FRFamides and FMRFamide and their release, probably from the processes of the sensory neurons in the muscle. Both centrally and in the periphery, the FRFamides and FMRFamide act in distinct ways, apparently through distinct mechanisms, and nevertheless, from an overall functional perspective, their actions are complementary. Together, the FRFamides and FMRFamide convert feeding motor programs from ingestive to egestive and depress feeding muscle contractions. We conclude that these structurally related peptides, although derived from different precursors, expressed in different neurons, and acting through different mechanisms, remain related to each other in the functional roles that they play in the system.
\end{abstract}

\section{Introduction}

Neuropeptides are the most diverse intercellular signaling molecules and are present in the nervous system in most, if not all, animals (Strand, 1999). This diversity and abundance has stimulated a search for basic principles that govern neuropeptide actions. The questions include the possibility that individual peptides may be dedicated to single behaviors, that different peptides may produce similar cellular responses and thus be able to substitute for each other's actions, and that several peptides may together produce a response that none of the peptides could produce alone.

One way to make sense of the apparent diversity of peptides is to group them based on structure similarity. Such groupings have made it possible to conduct comparative studies of peptide func-

\footnotetext{
Received July 9, 2009; revised Sept. 16, 2009; accepted Sept. 28, 2009.

This work was supported by National Institutes of Health Grants DA13330, NS31609, MH035564, and NS066587 and National Science Foundation Grant CHE 98-77071. We gratefully acknowledge the generous gift of Aplysia CDNA libraries from Dr. Gregg Nagle and Dr. Wayne Sossin. Some Aplysia were provided by the National Resource for Aplysia at the University of Miami under National Institutes of Health National Center for Research Resources Grant RR10294

Correspondence should be addressed to F. S. Vilim, Box 1065, Department of Neuroscience, Mount Sinai School of Medicine, New York, NY 10029. E-mail: ferdinand.vilim@mssm.edu.

DOI:10.1523/JNEUROSCI.3282-09.2010

Copyright $\odot 2010$ the authors $\quad 0270-6474 / 10 / 300131-17 \$ 15.00 / 0$
}

tion and address some of the questions of peptide specificity. Structurally related peptides derived from the same precursor protein are likely to be coreleased (Sossin et al., 1989) and often exert similar actions (Mahon et al., 1985; Lloyd et al., 1987a,b; Cropper et al., 1988; Vilim et al., 1994). In some cases, they can exert distinct but functionally convergent actions that together endow the overall response with features that the individual peptides do not produce (Brezina et al., 1996, 1997), but because peptides derived from the same precursor tend to be coreleased from the same neurons in a more or less fixed ratio, there is little flexibility in the coordination of this overall response (Vilim et al., 1996a,b). Such flexibility could potentially be achieved when structurally related peptides derived from different precursors are released from different neurons. Here we ask whether structurally related peptides derived from different precursors exert similar or different, perhaps functionally complementary, actions. Invertebrate nervous systems provide unique opportunities for studying the role of neuropeptides, at both the network and the single-cell level (Brezina and Weiss, 1997; Kupfermann, 1991; Marder et al., 1995; Nusbaum et al., 2001). Here we use the feeding system of Aplysia to examine the functional effects of the RFamide peptides FMRFamide and the FRFamides. 
Neuropeptides containing the C-terminal RFamide motif are among the most widely expressed peptides in the animal kingdom (Greenberg and Price, 1992; Dockray, 2004; Bechtold and Luckman, 2007, Li and Kim, 2008). Both FMRFamide and the FRFamides belong to the family of small RFamide peptides (Bechtold and Luckman, 2007). Both FMRFamide and FRFamides are present in the feeding system of Aplysia (Lloyd et al., 1987b; Cropper et al., 1994). Here we show that FMRFamide and the FRFamides are derived from different precursors expressed primarily in different neurons. We then investigate the functional effects of these peptides in the CNS and in the feeding periphery. We find that, at the system level, in both the CNS and the periphery, FMRFamide and the FRFamides exert functionally related actions. However, to a large extent, they achieve this system-level effect via differing, but functionally complementary, actions. Thus, our work indicates that a functional convergence can occur through divergent actions of structurally related peptides derived from different precursors. The convergence of central and peripheral actions of RFamides may also coordinate function of the CNS and the peripheral musculature.

\section{Materials and Methods}

Animals. Aplysia californica weighing 10-20 g were obtained from the University of Miami Aplysia Research Facility, and 100-350 g animals were obtained from Marinus and Pacific Biomarine. The animals were kept at $14^{\circ} \mathrm{C}$ in 150 gallon tanks containing artificial sea water. For electrophysiological experiments, animals were used within 1 week of arrival. For experiments measuring the release of the RFamides, animals were not fed for 3-5 $\mathrm{d}$ before the experiment.

Cloning. Standard molecular techniques (Sambrook et al., 1989) were used except when noted. The known cDNA sequence encoding the FMRFamide precursor (Schaefer et al., 1985) was used to generate PCR primers that were used to amplify the sequence from cDNA libraries. The amplified DNA was ligated into plasmids and subcloned into bacteria. Plasmids containing the cDNA encoding the FMRFamide precursor were identified by DNA cycle sequencing and used to generate probes for library screening, Northern blot analysis, and in situ hybridization. The cDNA encoding the FRFamide precursor of Aplysia has not been reported before; here it was identified using a modification of the seminested PCR technique described previously (Fujisawa et al., 1999; Furukawa et al., 2001; Proekt et al., 2005). A nested PCR strategy was used with two degenerate antisense oligonucleotide primers (dFRFa: CCR AAI CKR AAI ARI GCI CCI CC; dFRFb: CTC CCR AAY CKR ARI ARI GAI CC) deduced from the known amino acid sequences of two of the FRFamide peptides, FRFamides A and B (Cropper et al., 1994), in combination with two nested primers (M13rev: AGC GGA TAA CAA TTT CAC ACA GGA; T3 promoter: CGG AAT TAA CCC TCA CTA AAG G) directed against the flanking sequence of the vector used in construction of the Aplysia CNS cDNA library. Antisense, rather than sense, degenerate primers were chosen because all of the FRFamide peptides share the C-terminal FRFamide motif, and antisense primers will better target the unique $\mathrm{N}$-terminal, rather than the shared C-terminal, ends. Clones that contained additional sequence encoding FRFamide $\mathrm{C}$, the third FRFamide peptide that was previously biochemically identified (Cropper et al., 1994), were isolated and sequenced, and these clones were used to generate probes for library screening, Northern blot analysis, and in situ hybridization.

Northern blot analysis. Northern blot analysis was performed as described previously (Fujisawa et al., 1999; Furukawa et al., 2001, Proekt et al., 2005). Briefly, RNA was isolated from homogenized pooled ganglia using the acid-phenol method (Chomczynski and Sacchi, 1987). RNA from each ganglion type (buccal, cerebral, pleural, pedal, and abdominal) was fractionated separately using denaturing agarose gels (1.5\%) and transferred to nylon membranes (Biodyne B; Invitrogen). The RNA was immobilized with UV (Stratalinker; Stratagene) and visualized by staining with $0.02 \%$ methylene blue in $0.3 \mathrm{M} \mathrm{Na}$-acetate, $\mathrm{pH}$ 5.5. After washing out the excess stain with DEPC-treated water, the blot was scanned to document the amount of RNA transferred from each lane. After destaining with $1 \%$ SDS, 1 mM EDTA, and $50 \mathrm{~mm} \mathrm{Na}_{3} \mathrm{PO}_{4}, \mathrm{pH}$ 7.2, the blot was prehybridized for $1 \mathrm{~h}$ at $50^{\circ} \mathrm{C}$ using $50 \%$ formamide, $10 \%$ dextran sulfate, $7 \%$ SDS, $10 \mathrm{~mm}$ EDTA, $50 \mu \mathrm{g} / \mathrm{ml}$ salmon sperm DNA, and $250 \mathrm{~mm}$ $\mathrm{Na}_{3} \mathrm{PO}_{4}, \mathrm{pH}$ 7.2. Heat-denatured, random-primed (New England Biolabs), $\left[{ }^{32} \mathrm{P}\right] \mathrm{dCTP}-$ labeled cDNA probe (either FMRFamide or FRFamide) was added, and hybridization was continued overnight at $50^{\circ} \mathrm{C}$. Blots were washed twice for $15 \mathrm{~min}$ at room temperature with $2 \times$ SSPE and $0.1 \%$ SDS, washed for $60 \mathrm{~min}$ at $50^{\circ} \mathrm{C}$ with $0.1 \times$ standard saline phosphate EDTA (SSPE) and $0.1 \%$ SDS, and exposed to film. Autoradiographs and methylene blue-stained blots were scanned into Photoshop (Adobe Systems) and compiled into figures.

In situ hybridization. In situ hybridization was performed as described previously (Vilim et al., 2001). Ganglia were digested with 1\% protease type IX (Sigma-Aldrich) in $10 \mathrm{ml}$ of artificial sea water (ASW) (in mM: $460 \mathrm{NaCl}, 10 \mathrm{KCl}, 55 \mathrm{MgCl}_{2}, 11 \mathrm{CaCl}_{2}$, and 10 HEPES, $\mathrm{pH}$ 7.6) for $3 \mathrm{~h}$ at room temperature (with rocking) to facilitate the removal of the sheath. After digestion, the ganglia were washed with ASW and fixed overnight at $4^{\circ} \mathrm{C}$ with $4 \%$ paraformaldehyde (Electron Microscopy Sciences) in PBS. The ganglia were then washed, desheathed, and dehydrated in an ascending ethanol series. After rehydration in a descending ethanol series, the ganglia were prehybridized for $6 \mathrm{~h}$ and then hybridized overnight at $50^{\circ} \mathrm{C}$ in HYB buffer ( $50 \%$ formamide, 5 mm EDTA, $5 \times$ SSC, $1 \times$ Denhardt's solution, $0.1 \%$ Tween 20 , and $0.5 \mathrm{mg} / \mathrm{ml}$ yeast tRNA) containing $2 \mu \mathrm{g} / \mathrm{ml}$ digoxigenin-labeled cRNA probes made from FMRFamide or FRFamide cDNA templates. After washout of the probes, the ganglia were then incubated overnight at $4^{\circ} \mathrm{C}$ with a 1:200 dilution of alkaline phosphataseconjugated anti-digoxigenin antibody (Roche Molecular Biochemicals) in PBS containing $0.1 \%$ Tween 20 (PBT), $0.2 \%$ bovine serum albumin (BSA), and $1 \%$ normal goal serum. After washes with PBT to remove unbound antibody, the ganglia were washed with detection buffer $(100$ $\mathrm{mm} \mathrm{NaCl}, 50 \mathrm{~mm} \mathrm{MgCl} 2,0.1 \%$ Tween 20, $1 \mathrm{~mm}$ levamisol, and $100 \mathrm{~mm}$ Tris- $\mathrm{HCl}, \mathrm{pH}$ 9.5) and developed with $4.5 \mu \mathrm{l}$ of nitroblue tetrazolium and $3.5 \mu \mathrm{l}$ of 5-bromo-4-chloro-3-indolyl phosphate (Roche Molecular Biochemicals, Indianapolis, IN) in $1 \mathrm{ml}$ of detection buffer. The staining reaction was monitored visually and stopped by washing with PBT when the level of staining was adequate. The stained ganglia were observed and photographed using a Nikon microscope (Morrell Instruments) with epi-illumination against a white background. Photographs were taken with a Nikon CoolPix 990 digital camera, imported into Photoshop, and compiled into figures.

Antibodies. Antibodies were generated to several peptides that were derived from the amino acid sequences of the FMRFamide and FRFamide precursor proteins. The peptide antigens were prepared as described previously (Fujisawa et al., 1999; Furukawa et al., 2001; Li et al., 2001; Sweedler et al., 2002). Briefly, the antigen was prepared by coupling synthetic peptide (SynPep) to BSA (catalog \#A0281; Sigma-Aldrich) using 1-ethyl-3-(dimethylaminopropyl)carbodiimide (EDC) (catalog \#E7750; Sigma-Aldrich). The coupling was performed in $1 \mathrm{ml}$ of $50 \mathrm{~mm} \mathrm{NaH}_{2} \mathrm{PO}_{4}$, pH 7.2, containing $10 \mathrm{mg}$ of BSA, $1 \mathrm{mg}$ of peptide, and $25 \mathrm{mg}$ of EDC. The mixture was allowed to react overnight at $4^{\circ} \mathrm{C}$, and the coupled antigen was purified from the reaction using a Microcon-30 spinning at 13,800 $\times$ $g$ for $30 \mathrm{~min}$ at $4^{\circ} \mathrm{C}$. The retentate was washed four times with $0.4 \mathrm{ml}$ of 50 $\mathrm{mM} \mathrm{NaH}_{2} \mathrm{PO}_{4}, \mathrm{pH} 7.2$, then resuspended in $0.5 \mathrm{ml}$ of the same buffer, and transferred to a new tube. For each antigen, two male Sprague Dawley rats (250-300 g; Taconic Farms) were immunized by intraperitoneal injection with either $12.5 \mu \mathrm{l}(\sim 250 \mu \mathrm{g}$; rat 1$)$ or $25 \mu \mathrm{l}(\sim 500 \mu \mathrm{g}$; rat 2$)$ of antigen in an emulsion of $0.3 \mathrm{ml}$ of PBS and $0.3 \mathrm{ml}$ of Freund's complete adjuvant. At days 21 and 42, the rats were boosted by intraperitoneal injection with either $6.25 \mu \mathrm{l}(\sim 125 \mu \mathrm{g}$; rat 1$)$ or $12.5 \mu \mathrm{l}(\sim 250 \mu \mathrm{g}$; rat 2$)$ of antigen in an emulsion of $0.3 \mathrm{ml}$ of PBS and $0.3 \mathrm{ml}$ of Freund's incomplete adjuvant. The animals were killed by decapitation at $49 \mathrm{~d}$, and the blood was harvested and processed for serum. Sera were aliquoted, frozen and lyophilized, or stored at $4^{\circ} \mathrm{C}$ with EDTA ( $25 \mathrm{~mm}$ final concentration) and thimerosal ( $0.1 \%$ final concentration) added as stabilizers. For antibodies that produced immunostaining, specificity was confirmed by preincubation of the primary antibody with $100 \mu \mathrm{M}$ of the corresponding synthetic peptide, which abolished the staining (data not shown). For some of the antigens that successfully produced specific antibodies in the 
rats, antibodies to the same antigens were then produced in rabbits (Strategic Biosolutions). The rabbit antibodies were used in combination with the rat antibodies for simultaneous immunostaining of two antigens in the same preparation. A rabbit antibody generated to FRFamide A was found not to distinguish well between FRFamide and FMRFamide but was used in radioimmunoassays to measure RFamide release in the accessory radula closer (ARC) muscle (see Fig. 7) and in immunostaining of the muscle (see Fig. 8).

Immunostaining. Immunostaining was performed as described previously (Vilim et al., 1996a; Fujisawa et al., 1999; Furukawa et al., 2001, Proekt et al., 2005). Tissues were fixed in freshly prepared fixative (4\% paraformaldehyde, $0.2 \%$ picric acid, $25 \%$ sucrose, and $0.1 \mathrm{M} \mathrm{NaH}_{2} \mathrm{PO}_{4}$, $\mathrm{pH}$ 7.6) for either $3 \mathrm{~h}$ at room temperature or overnight at $4^{\circ} \mathrm{C}$. After washes with PBS to remove the fixative, ganglia from large animals were desheathed to expose the neurons. Double-labeling experiments were performed using primary antibodies generated to different antigens in different species (rat and rabbit). Two different secondary antibodies conjugated to either rhodamine red-x or fluorescein (Jackson ImmunoResearch) were used to visualize the different primary antibodies. The immunostained preparations were viewed and photographed on a Nikon microscope equipped with epifluorescence. The images were collected using filters with characteristics appropriate for distinguishing between the fluorophores. In Figures $2 D$ and 8 , the negatives of the images are shown to enhance visibility.

Radiolabeling and HPLC purification of FRFamides from buccal sensory neurons. In situ radiolabeling and reverse-phase HPLC of FRFamide peptides was performed as described previously (Cropper et al., 1994). For radiolabeling, five buccal ganglia were incubated individually with $1 \mathrm{mCi}$ $\left[{ }^{3} \mathrm{H}\right]$ phenylalanine (GE Healthcare) for $24 \mathrm{~h}$ at $18^{\circ} \mathrm{C}$ in $1 \mathrm{ml}$ of $50 \%$ ASW/50\% sterile $(0.2 \mu \mathrm{m}$ filtered $)$ hemolymph with $1 \mu \mathrm{m}$ antibiotics and $25 \mu \mathrm{M}$ colchicine. After incubation, the ganglia were rinsed with ASW to remove the bulk of the unincorporated radioactivity. Buccal sensory neuron clusters were dissected from the labeled ganglia and deposited in a microtube containing $5 \mu \mathrm{l}$ of $0.015 \mathrm{M}$ trifluoroacetic acid (TFA) and 5 nmol of each of the five synthetic FRFamides A-E. The microtube was heated at $95^{\circ} \mathrm{C}$ for $10 \mathrm{~min}$ to inactivate proteases and liberate the radiolabeled peptides. The extract was applied to a C18 cartridge (C18 Sep-Pak cartridge; Waters Associates). Unbound radioactivity was eluted by washing the cartridge with $3 \mathrm{ml}$ of $\mathrm{H}_{2} \mathrm{O} / 0.015 \mathrm{M}$ TFA, followed by $5 \mathrm{ml}$ of $5 \% \mathrm{CH}_{3} \mathrm{CN} / 0.015 \mathrm{~m}$ TFA. The bound radiolabeled and synthetic peptides were then eluted with $5 \mathrm{ml}$ of $80 \% \mathrm{CH}_{3} \mathrm{CN} / 0.015 \mathrm{~m}$ TFA. The eluate was lyophilized, resuspended in $0.01 \mathrm{M} \mathrm{TFA}$, and subjected to sequential HPLC. Different gradients and counterions were designed to separate the FRFamides and allow them to be identified by their different retention times. Radiolabeled peptides were detected by scintillation counting of the HPLC-separated fractions. Synthetic peptides were detected by absorbance measurements with a V-4 flow spectrophotometer (ISCO) at $215 \mathrm{~nm}$. Coelution of radioactive peaks and absorbance peaks in the final stages of purification was taken as evidence that the peptides were synthesized by the buccal sensory neurons.

Purification of FMRFamide from ARC muscle extracts. FMRFamide was identified in extracts of the ARC muscle as described previously (Lloyd et al., 1987b; Cropper et al., 1988; Vilim et al., 1994). Briefly, ARC muscles were dissected and pooled, and peptides were extracted by homogenization in boiling $0.1 \mathrm{~m}$ acetic acid, followed by centrifugation to remove insoluble material. The peptides were initially purified using C18 cartridges and eluted as described above. The eluate was lyophilized, resuspended, and run on sequential stages of HPLC using different conditions to separate the peptides contained in the extract. Specifically, in the four HPLC stages shown in Figure $9 A-D$, the conditions were as follows: $A$ : Zorbax C8 column, solvent A included $0.01 \mathrm{~m}$ heptafluorobutyric acid (HFBA) in $\mathrm{H}_{2} \mathrm{O}$, solvent $\mathrm{B}$ included $0.01 \mathrm{M} \mathrm{HFBA}$ in $\mathrm{CH}_{3} \mathrm{CN}$, and the gradient included $20-35 \%$ solvent $\mathrm{B}$ in $120 \mathrm{~min}$; $\mathrm{B}$ : Zorbax C8 column, solvent $A$ included $0.01 \mathrm{M}$ TFA in $\mathrm{H}_{2} \mathrm{O}$, solvent $\mathrm{B}$ included $0.01 \mathrm{~m}$ TFA in $\mathrm{CH}_{3} \mathrm{CN}$, and the gradient included $20-32 \%$ solvent $\mathrm{B}$ in $48 \mathrm{~min}$; $\mathrm{C}$ : Aquapore RP-300 column, solvent $\mathrm{A}$ included $0.1 \mathrm{M}$ triethylammonium acetate (TEAA) in $\mathrm{H}_{2} \mathrm{O}$, solvent $\mathrm{B}$ included $0.1 \mathrm{M}$ TEAA in $80 \% \mathrm{CH}_{3} \mathrm{CN}$ and $20 \% \mathrm{H}_{2} \mathrm{O}$, and the gradient included $15-30 \%$ solvent $\mathrm{B}$ in $60 \mathrm{~min} ; \mathrm{D}$ :
Aquapore RP-300 column, solvent A included 0.01 M TFA in $\mathrm{H}_{2} \mathrm{O}$, solvent $\mathrm{B}$ included $0.01 \mathrm{~m}$ TFA in $\mathrm{CH}_{3} \mathrm{CN}$, and the gradient included $10-45 \%$ solvent B in $35 \mathrm{~min}$. At each stage, a portion of each HPLC fraction was bioassayed in the ARC neuromuscular preparation (see below) for its ability to depress motor neuron-elicited contractions of the ARC muscle. Selected bioactive fractions were rechromatographed in the following stage of HPLC. The purification was continued until the HPLC chromatogram showed a single absorbance peak that corresponded to a bioactive fraction. The purified bioactive peptide was then sequenced using the Edman method.

Cell culture. After treatment with 1\% protease in ASW supplemented with antibiotics, buccal ganglia were desheathed and neurons were manually dissociated from the S1 and S2 clusters. The neurons were cultured at low density in ASW for $48 \mathrm{~h}$ at $14^{\circ} \mathrm{C}$ on ITO microscope slides for matrix-assisted laser desorption/ionization (MALDI) imaging (Bruker Daltonics) pretreated with poly-L-lysine as described previously (Romanova et al., 2004). Mature cultures were exposed to $30 \%$ glycerol in ASW for $30 \mathrm{~min}$ (Rubakhin and Sweedler, 2007), then all liquid was aspirated from the slides by vacuum, and minute volumes of concentrated DHB matrix solution (2,5-dihydroxybenzoic acid and $50 \mathrm{mg} / \mathrm{ml}$ $80 \%$ acetone) were manually applied with a glass micropipette onto the cultured neurons visible in transmitted light under a dissecting microscope. MALDI mass spectra were obtained as described below.

Matrix-assisted laser desorption/ionization mass spectrometry. Freshly dissected buccal ganglia were desheathed as described above. They were then superfused with $30 \%$ glycerol in ASW, and individual neurons or neuron clusters were manually isolated using electrolytically sharpened tungsten needles and transferred onto MALDI sample plates using plastic micropipettes. Excess liquid was aspirated by vacuum, and $0.3-0.5 \mu \mathrm{l}$ of concentrated DHB matrix solution was added to the spot. MALDI timeof-flight (TOF) mass spectra of the freshly isolated neurons were obtained in reflectron mode on a Voyager DE STR mass spectrometer (Applied Biosystems) equipped with a pulsed nitrogen laser and delayed ion extraction. The cultured neurons were analyzed using a Bruker Ultraflex II mass spectrometer (Bruker Daltonics) in reflectron mode with external calibration and high-precision calibration feature. In both cases, instrumental settings were optimized to achieve high sensitivity of detection in the mass range of 500-6000 Da.

To analyze the peptide content of esophageal nerves, the nerves were manually dissected, rinsed with water, and transferred to MALDI target plates (either Applied Biosystems gold-plated targets or Bruker Daltonics PAC 384 prespotted targets). Extraction was performed on the target surface with $\sim 0.5 \mu \mathrm{l}$ of acidified acetone ( 40 parts acetone/ 6 parts $\mathrm{H}_{2} \mathrm{O} / 1$ part $\mathrm{HCl}, 12 \mathrm{~m})$. After extraction, $\alpha$-cyano-4-hydroxycinnamic acid MALDI matrix, mixed in $70 \% \mathrm{CH}_{3} \mathrm{CN}$ with $0.01 \%$ TFA, was applied to the sample spot. MALDI-TOF mass spectrometry (MS) was performed with either the Voyager DE STR mass spectrometer (Applied Biosystems) or the Bruker Ultraflex II mass spectrometer. Mass spectra were initially calibrated externally with peptide standards and in some cases recalibrated with spiked internal calibration standards.

Electrophysiology. Electrophysiology was performed as described previously (Proekt et al., 2005). Animals weighing 150-250 g were anesthetized by injection of isotonic $\mathrm{MgCl}_{2}(337 \mathrm{~mm})$. The cerebral and buccal ganglia were pinned out in a Sylgard-lined recording dish (volume of $\sim 1.5 \mathrm{ml}$ ) and desheathed to expose the neurons of interest. The preparation was continuously superfused at $\sim 0.3 \mathrm{ml} / \mathrm{min}$ with ASW cooled to $14-17^{\circ} \mathrm{C}$. Intracellular recordings were made with glass microelectrodes filled with $2 \mathrm{M} \mathrm{K}$-acetate plus $200 \mathrm{~mm} \mathrm{KCl}$ and beveled to $8-15 \mathrm{M} \Omega$. In some cases, the tip of the microelectrode was filled with $3 \%$ carboxyfluorescein, which was injected into the neuron by passing negative current for $15 \mathrm{~min}$. Intracellular voltage recordings were amplified with an Axoclamp 2B amplifier (Molecular Devices). Extracellular recordings and stimulation were performed using suction electrodes manufactured from polyethylene tubing connected to a differential alternating current amplifier (model 1700; A-M Systems). All signals were acquired simultaneously at $5 \mathrm{kHz}$ with a Digidata 1322A data-acquisition system (Molecular Devices). The signals were then analyzed using Clampfit 9 (Molecular Devices). Axum 5 (Mathsoft) and SigmaPlot 8 (Systat Software) were used to generate figures. 
Characterization of feeding motor programs. Standard methods and criteria were used to elicit and characterize feeding motor programs (see Fig. 5A). In Aplysia, each feeding motor program begins with the radula protraction phase, followed by the radula retraction phase (Hurwitz and Susswein, 1996; Hurwitz et al., 1996, 1997; Jing and Weiss, 2001, 2002; Morgan et al., 2002; Koh et al., 2003; Proekt and Weiss, 2003; Proekt et al., 2004). In vitro, the protraction phase is defined to be coincident with a characteristic burst of electrical activity in the extracellular recording from the I2 nerve (Hurwitz and Susswein, 1996; Hurwitz et al., 1996, 1997), and the retraction phase is defined as the period between the termination of the I 2 burst and the termination of another characteristic burst in the extracellular recording from buccal nerve 2 (Morton and Chiel, 1993a,b). In intracellular recordings, the retraction phase also coincides with a sustained depolarization of the neurons B4/5 (Warman and Chiel, 1995; Jing and Weiss, 2001; Morgan et al., 2002). Ingestive and egestive motor programs are then differentiated by the phasing of radula closure activity with respect to the protraction and retraction phases. Ingestive programs are characterized by radula closure activity mainly in the retraction phase, and egestive programs are characterized by radula closure activity mainly in the protraction phase (Morton and Chiel, 1993a,b; Jing and Weiss, 2001, 2002; Morgan et al., 2002; Sasaki et al., 2007, 2008; Wu et al., 2007). Radula closure was monitored by the firing of the radula closer motor neurons B8, recorded either with an intracellular electrode or extracellularly in the radula nerve (Morton and Chiel, 1993a,b). The feeding motor programs were elicited by intracellularly stimulating the command-like cerebral-buccal interneuron 2 (CBI-2) (Rosen et al., 1991; Morgan et al., 2000, 2002; Jing and Weiss, 2001) to fire action potentials at $10 \mathrm{~Hz}$ for the duration of the protraction phase, with an 1 min rest interval between the end of the retraction phase and the next CBI-2 stimulation.

$A R C$ neuromuscular preparation. Motor neuron-elicited contractions of the ARC muscle were recorded as described previously (Weiss et al., 1978, 1979; Cropper et al., 1994; Orekhova et al., 2003). Briefly, the buccal ganglion and an ARC muscle were dissected from the animal while maintaining buccal nerve 3 , their connecting nerve, intact. The buccal ganglion was pinned out in a Sylgard-lined dish, and the rostral surface was desheathed to expose neurons B15 and B16, the two motor neurons of the ARC muscle (Cohen et al., 1978). The ARC muscle was pinned out in a separate subchamber sealed off with silicone grease. A length transducer (model 60-3000; Harvard Apparatus) was attached to the ARC muscle to measure its tension (see Fig. 10) or length (see Fig. 11). Excitatory junctional potentials (EJPs) were recorded with standard intracellular electrodes from the proximal part of the ARC muscle, which was pinned to minimize its contractions, while contractions continued normally in the distal part of the muscle (Weiss et al., 1978). The ARC motor neurons were intracellularly stimulated to fire short bursts of action potentials so as to produce contractions of moderate amplitude. Peptides were added to the subchamber containing the muscle only.

$A R C$ peptide release: preparation and radioimmunoassay. Release of RFamides in the ARC muscle was measured as described previously (Vilim et al., 1996a,b, 2000). Briefly, the ARC neuromuscular preparation was dissected, pinned, and desheathed as described above except that buccal nerve 3 was run through a slit in the side of the dish containing the buccal ganglion so that the ARC muscle was hanging free. The muscle was cannulated for constant perfusion through its artery and then was encased in a combination of silicone grease and Parafilm so that drops of the outflowing perfusate could form and be collected. The configuration also allowed monitoring of the isotonic contractions of the muscle as described above. The temperature was maintained at $\sim 15^{\circ} \mathrm{C}$ with the aid of an air conditioner. The buccal ganglion in the dish was bathed in $75 \%$ ASW and $25 \%$ isotonic $\mathrm{MgCl}_{2}$ to prevent spontaneous activity. The ARC motor neurons were stimulated intracellularly, or buccal nerve 3 was stimulated extracellularly, in bursts with controlled duration and frequency. Using a peristaltic pump, the muscle was perfused with ASW at a slow rate to allow the released peptides to accumulate to levels that could be measured with radioimmunoassay (RIA). Drops of the perfusate were collected directly into the tubes that were then used to perform the RIA. The tubing in the peristaltic pump was of the shortest length and the smallest inner diameter to minimize the dead volume for the perfusion of pharmacological agents and ASW with different $\mathrm{Ca}^{2+}$ concentrations.

RIAs were performed as described previously (Vilim et al., 1996a,b, 2000). The antibody used in the RIA was generated in rabbit against FRFamide A coupled to BSA as described above. The IgG fraction was isolated from the serum using the protein A method because the unpurified serum failed to provide an assay that was sensitive enough. The purified IgG was added to RIA buffer (154 mM NaCl, $10 \mathrm{mM} \mathrm{Na}_{2} \mathrm{HPO}_{4}$, $50 \mathrm{~mm}$ EDTA, $0.25 \mathrm{~mm}$ thimerosal, and 1\% BSA, pH 7.5) at a concentration of $200 \mathrm{ng} / \mathrm{ml}$ and was able to bind $20 \%$ of the counts after a $3 \mathrm{~d}$ incubation. The trace used in the RIA was made from desaminotyrosinated FRFamide A iodinated with ${ }^{125}$ I and purified with HPLC. HPLC fractions containing the monoiodinated peptide were pooled, lyophilized, and resuspended in RIA buffer such that $100 \mu \mathrm{l}$ contained 10,000 cpm in the gamma counter.

Previous work (Vilim et al., 1996a,b) showed that nonspecific binding of peptides resulted in substantial losses of material from the perfusate drops. This problem was solved by collecting the perfusate into $100 \mu \mathrm{l}$ of the trace and immediately adding $100 \mu \mathrm{l}$ of the antibody solution (containing BSA). After a $3 \mathrm{~d}$ incubation, unbound trace was adsorbed using dextran-coated activated charcoal and spun in a centrifuge, and the bound trace was decanted into a fresh tube. A dilution series of FRFamide A was used to calibrate the assay and generate a standard curve. The entire experiment and the standard curve were run in parallel to minimize variation. The bound trace was measured in a gamma counter, and the counts were converted to femtomoles of peptide using the standard curve in a data analysis program (Kaleidagraph; Synergy Software).

Membrane ion currents in single ARC muscle fibers. Membrane ion currents were recorded as described previously (Brezina, 1994; Brezina et al., 1994c; Cropper et al., 1994). Briefly, single fibers were dissociated from the ARC muscle by collagenase treatment. A selected fiber was impaled close to one end with an intracellular microelectrode and held suspended from it in a fast-flowing stream of solution (ASW). Through the microelectrode, the fiber was voltage clamped using the discontinuous single-electrode technique. Quasi-steady-state current-voltage $(I-V)$ relations were obtained by sweeping the membrane voltage from (nominally) -100 to $-30 \mathrm{mV}$ at a slow rate $(14 \mathrm{mV} / \mathrm{s})$, repetitively every $10 \mathrm{~s}$ before and during application of the peptides in the solution stream (the timing of a complete experiment can be seen in Fig. 12A).

\section{Results \\ Cloning and molecular analysis of FRFamide and FMRFamide precursor cDNAs}

To define the full spectrum of the neuropeptides derived from the FRFamide and FMRFamide precursor proteins in Aplysia, we undertook a molecular analysis of the cDNAs encoding the precursors. After establishing that there were in fact separate FRFamide and FMRFamide precursors, we sought to determine, in particular, whether FRFamide peptides could be derived from an FMRFamide precursor or vice versa.

The cDNA sequence encoding the Aplysia FRFamide precursor has not been reported previously, although three FRFamide peptides have been characterized and sequenced (Cropper et al., 1994). We sought to clone the precursor cDNA to identify its full complement of peptides as well as to provide in situ hybridization probes to map the expression of the mRNA encoding the FRFamides. To clone the precursor cDNA, we used a semi-nested rapid amplification of cDNA ends PCR strategy on a CNS cDNA library using degenerate primers designed to the amino acid sequence of the known FRFamide peptides. We then screened the phage library to determine the full-length cDNA sequence that encodes the FRFamide precursor (GenBank accession number GU263310). The FRFamide precursor, whose amino acid sequence is shown in Figure 1, encodes two copies of FRFamide A (GGALFRFamide) and single copies of FRFamide B (GSLFRFamide), FRFamide C (STLFRFamide), FRFamide D 


\begin{tabular}{lr} 
meprpitlslavllaalcttcaTGS & 25 \\
AKLVSSSEDNTNSHTDGLTRDHQPQ & 50 \\
KRSAAAILSPADDALLVRADEGEEE & 75 \\
GVGGSYPGIPLSLPGTADKRSTLFR & 100 \\
FGKRGAGTLFRFGKRGSLFRFGKRG & 125 \\
GALFRFGKRGGALFRFGKRGVASGS & 150 \\
\hline GAFPLADDSDVKRTLFRFGKRSNLD & 175 \\
LLRDVLSQYQLSAYPDAYPDAYPDA & 200 \\
YIDDVDSKRGVDGFHWGDDQ & 220
\end{tabular}

Figure 1. Amino acid sequence and processing of the FRFamide precursor protein. A predicted hydrophobic signal peptide (Nielsen et al., 1997) is shown in lowercase letters, and dibasic cleavage sites (Seidah and Chretien, 1999) are shown in bold. The precursor contains six copies of structurally related FRFamide peptides (underlined), as well as multiple linker peptides.

(GAGTLFRFamide), and FRFamide E (TLFRFamide). FRFamides $\mathrm{A}-\mathrm{C}$ are the three previously known peptides, but the cloning of the precursor thus suggests that two additional structurally related peptides, FRFamides D and E, should also be synthesized. In addition, the FRFamide precursor encodes multiple connecting (linker) peptides that do not show any structural similarity to the FRFamides. The amino acid sequence of the FRFamide precursor clearly shows that no FMRFamide peptides can be produced from it. BLASTP analysis with the FRFamide precursor sequence revealed a significant homology to a Lymnaea RFamide precursor (GenBank accession number AY773478) (Hoek et al., 2005) that is likely to be the ortholog of the Aplysia FRFamide precursor.

The cDNA sequence encoding the FMRFamide precursor of Aplysia has been known for almost two decades (Schaefer et al., 1985). We recloned this precursor by library screening and PCR to provide probes for in situ hybridization. In addition, we sought to determine whether the FMRFamide gene in Aplysia is alternatively spliced, as it is in another mollusk, Lymnaea stagnalis (Santama and Benjamin, 2000), to produce another RFamide precursor that might perhaps encode FRFamide peptides. Despite numerous attempts using library screening and PCR, we failed to detect any alternative splice forms of the FMRFamide gene. The known FMRFamide precursor encodes 28 copies of FMRFamide, a single copy of FLRFamide, and numerous acidic linker peptides. Inspection of the predicted amino acid sequence suggested that this precursor may produce an additional, hitherto unrecognized RFamide (pQSFLCDDSELCENGYLRFamide, with an internal disulfide bond between the two cysteines). However, analysis of MALDI mass spectra from neurons and nerves that contain FMRFamide (see below) failed to detect substantial peaks corresponding to the predicted mass of this peptide. In addition, antibodies directed against a synthetic peptide with this sequence failed to produce any clear immunostaining in the CNS of Aplysia. Thus, this additional peptide is unlikely to be synthesized in significant amounts. In an unrelated ongoing project in our laboratories, we have performed exhaustive liquid chromatography electrospray ionization tandem mass spectrometry experiments on literally hundreds of Aplysia CNS and have characterized almost 1000 peptides; we never detected this specific peptide in those ongoing experiments. Thus, it either is present below our detection limit or forms a complex that we are not recognizing as part of this precursor. Altogether, the molecular analysis suggests that the FMRFamide gene of Aplysia is not likely to give rise to significant quantities of additional neuropeptides and, in particular, to FRFamide peptides.
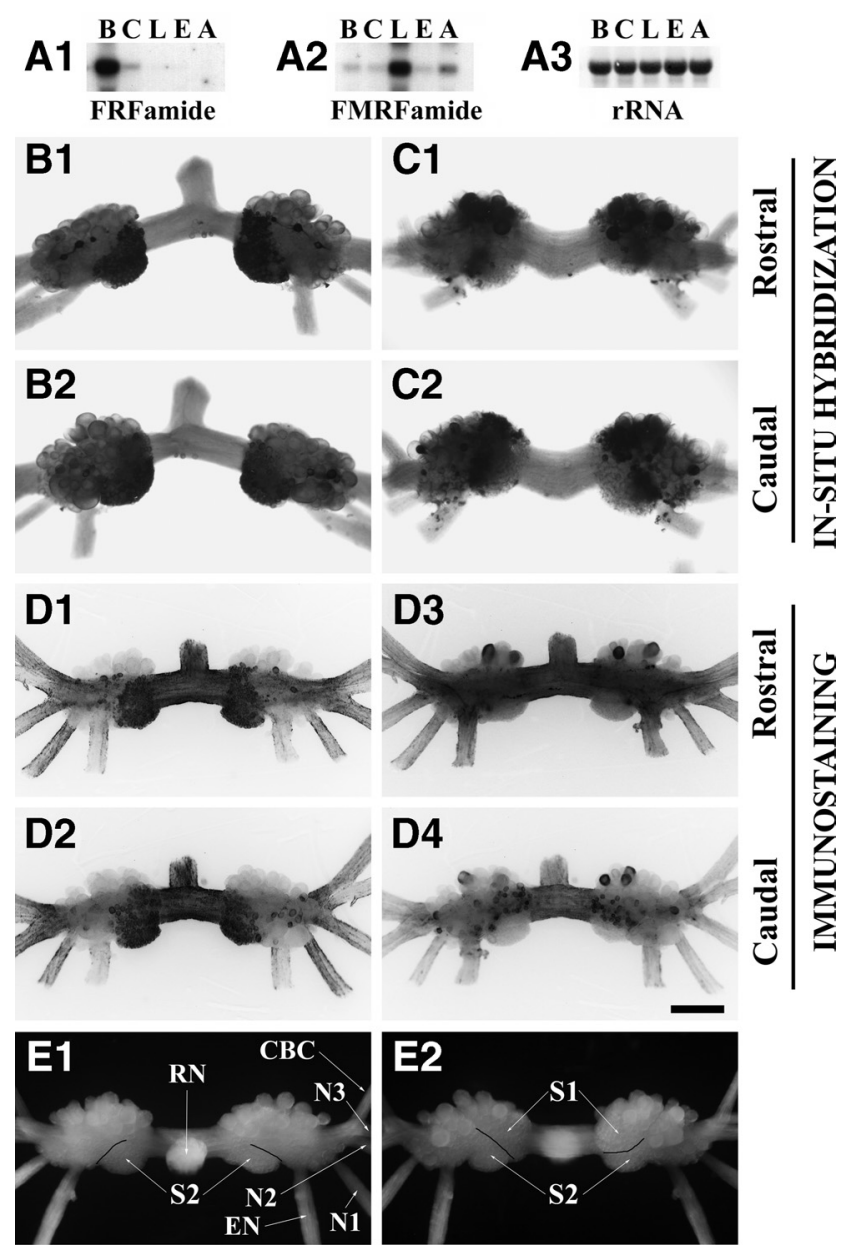

Figure 2. Mapping of FRFamide and FMRFamide precursor expression in the central ganglia of Aplysia and in neurons of the buccal ganglion. $A$, Northern blot analysis of the distribution of FRFamide and FMRFamide precursor mRNA in the different central ganglia of $A$ plysia (B, buccal; $C$, cerebral; $L$, pleural; $E$, pedal; $A$, abdominal). The highest levels of expression are in the buccal ganglion for the FRFamide precursor mRNA (A1) and in the pleural ganglia for the FMRFamide precursor mRNA (A2). However, the FMRFamide precursor mRNA is detectable in all of the ganglia, including the buccal ganglion. $A 3$, rRNA stained with methylene blue shows that equal amounts of total RNA were loaded in all lanes. $\boldsymbol{B}, \boldsymbol{C}$, In situ hybridization showing the distribution of FRFamide and FMRFamide precursor mRNA in neurons of the buccal ganglion. $\mathbf{B 1}$, FRFamide in situ hybridization staining of the rostral surface. B2, FRFamide in situ hybridization staining of the caudal surface. C1, FMRFamide in situ hybridization staining of the rostral surface. C2, FMRFamide in situ hybridization staining of the caudal surface. $\boldsymbol{B}$ and $\boldsymbol{C}$ show different ganglia. D, Immunostaining showing the distribution of FRFamide and FMRFamide precursor peptide in neurons and processes of the buccal ganglion. D1, FRFamide immunostaining of the rostral surface. D2, FRFamide immunostaining of the caudal surface. D3, FMRFamide immunostaining of the rostral surface. D4, FMRFamide immunostaining of the caudal surface. The panels in $\boldsymbol{D}$ all show the same ganglion with two different fluorophores, and the immunofluorescence is shown in negative for enhanced visibility. Scale bar, $500 \mu \mathrm{m}$. $\boldsymbol{E}$, Desheathed unstained buccal ganglion showing the location of the $\mathrm{S} 1$ and $\mathrm{S} 2$ clusters of sensory neurons and the designation of the buccal nerves ( $C B C$, cerebrobuccal connective; RN, radula nerve; $E N$, esophageal nerve; N1, nerve 1; N2, nerve 2; N3, nerve 3). E1, Rostral surface. E2, Caudal surface.

\section{Distributions of neurons expressing the FRFamide and FMRFamide precursors}

As a first step, we determined the expression of the FRFamide and FMRFamide precursor mRNAs in the different central ganglia of Aplysia using Northern blot analysis (Fig. 2A). This analysis showed that the FRFamide precursor is most highly expressed in the buccal ganglion (Fig. 2A1), whereas the FMRFamide precursor is most highly expressed in the pleural ganglia, although it is also expressed in the buccal ganglion (Fig. 2A2). This result gave 
an early indication of a differential expression of the two precursors. This differential expression was helpful in determining the specificity of the antibodies that we generated to selectively map the expression of the peptides derived from each precursor (see below).

As the next step, we determined the distributions of neurons expressing the FRFamide and FMRFamide precursor mRNAs in the different ganglia with in situ hybridization (Eberwine et al., 1994). This has been done previously for FMRFamide (Ono and McCaman, 1992) but not for FRFamide. Here we will focus just on the expression in the buccal ganglion, the principal ganglion of the feeding system.

As shown in Figure 2E, the buccal ganglion can be grossly divided into two main neuronal clusters, dorsal and ventral. The ventral cluster contains larger somata, which are generally motor neurons. The dorsal cluster contains smaller somata, which are generally sensory neurons, although some are interneurons. The dorsal cluster can be further subdivided into the S1 and S2 sensory neuron clusters (Fiore and Meunier, 1975). The S2 cluster spans the rostral and caudal aspects of the ventral buccal ganglion and contains somewhat smaller somata than the S1 cluster. The S1 cluster is located on the medial aspect of the caudal surface. Figure $2 E 1$ also shows the position of the buccal nerves referred to here. These nerves contain both afferent sensory and efferent motor axons.

In the buccal ganglion, the distributions of neurons expressing the FRFamide and FMRFamide precursor mRNAs were at least partly distinct. Figure $2, B$ and $C$, shows rostral $(B 1, C 1)$ and caudal $(B 2, C 2)$ views of buccal ganglia stained (using digoxigenin nucleotide hybridization, alkaline-phosphatase/nitrobluetetrazolium-chloride/5-bromo-4-chlor-indolyl-phosphate visualization) for the FRFamide (left column) and FMRFamide (right column) precursor mRNAs. The most striking difference is that large somata in the ventral motor neuron cluster stain for FMRFamide but not for FRFamide. Some motor neurons in the ventral cluster have indeed been shown biochemically to synthesize FMRFamide (Lloyd et al., 1987b; Church and Lloyd, 1991). In the sensory neuron clusters, the S2 cluster stains heavily for FRFamide but not FMRFamide. Both RFamides are expressed in the $S 1$ cluster, although the distributions appear to differ in detail. The use of different ganglia for the FRFamide and FMRFamide staining in Figure 2, $B$ and $C$, makes it difficult, however, to determine the true extent to which the two RFamides are coexpressed in individual neurons.

To map the extent of the coexpression more precisely, we sought to use double-labeled immunostaining to simultaneously and distinctly label the peptides derived from the FRFamide and FMRFamide precursors. To accomplish this, we first had to produce antibodies specific to the peptides derived from each precursor. The sequence similarity of the peptides derived from the two precursors made this difficult. We eventually were able to produce an antibody to FMRFamide in rat that did not stain neurons in the S2 cluster, in which the in situ hybridization showed the FRFamide precursor to be heavily expressed. We cannot exclude the possibility that the antibody we generated to FMRFamide recognizes additional RFamides, such as the FLRFamide derived from the FMRFamide precursor protein, but it does not appear to recognize any of the RFamides produced from the FRFamide precursor. To produce an antibody specific to the FRFamide precursor, we made an antibody in rabbits to a fragment of one of the linker peptides (GSYPGIPLSLPGTAD from the $\mathrm{FRF}_{\text {[53-93] }}$ peptide) that was detected in MALDI mass spectra of sensory neurons (Fig. 3C) and also buccal nerves, indicating that this peptide survived long enough to be transported. Generating the FMRFamide antibody in rats and the FRFamide antibody in rabbits enabled simultaneous detection of the FMRFamide and FRFamide peptides in the same preparation using secondary antibodies coupled to different fluorophores. Figure $2 D$ shows the distributions of neuronal somata on the rostral $(D 1, D 3)$ and caudal $(D 2, D 4)$ aspects of the buccal ganglion immunostaining for FRFamide (left column) and FMRFamide (right column). The distribution of neurons immunopositive for each RFamide matches well the distribution observed with in situ hybridization. To a large extent, the populations of neurons expressing the two RFamides appear to be non-overlapping, even in the S1 cluster in which most immunopositive neurons appear to stain for only FRFamide or only FMRFamide. However, we did observe a small number of S1 neurons that costained for both FRFamide and FMRFamide, suggesting that some buccal sensory neurons express both RFamide precursors.

An interesting feature of the immunostaining for both RFamides was the appearance of varicosities within the buccal nerves. Such varicosities were observed previously with immunostaining for another neuropeptide precursor, the myomodulin gene 2 derived peptide precursor (Proekt et al., 2005), and may be indicative of axo-axonic connections within the nerves themselves.

\section{Synthesis and processing of the FRFamide and FMRFamide peptides}

We used two approaches to define the processing of the RFamide precursors and to confirm the synthesis of the amidated peptides. The first approach combined radiolabeling with HPLC. Metabolic labeling of the RFamide peptides was accomplished by incubation of buccal ganglia with tritiated phenylalanine. The radiolabeled peptides were extracted from isolated S-cluster neurons and separated by HPLC. To identify the peptides, the retention times of the radiolabeled peptides were compared with those of added synthetic RFamides. Figure $3 A$ shows the first stage of the HPLC separation. The peaks from this first stage were then rechromatographed using different columns and counterions that were designed to separate the different RFamides, as shown in Figure 3B1-B4. Radioactive peaks corresponding to all five amidated FRFamides A-E were detected, providing evidence that all five peptides are indeed synthesized by the buccal sensory neurons. In Figure 3B2, two additional peaks of radioactivity were detected, one corresponding to FMRFamide (FMRF) and the other to FMRFamide with an oxidized methionine $\left(\mathrm{FM}^{\star} \mathrm{RF}\right)$.

The second approach that we used was MALDI-TOF MS (Li et al., 1998, 2000). In these experiments, there was no preincubation of the neurons and therefore reflects the in vivo synthesis of peptides. A representative mass spectrum of a single freshly isolated S-cluster neuron is shown in Figure 3C. The spectrum exhibits peaks with masses that correspond to all five amidated FRFamides A-E and four linker peptides that are predicted from the sequence of the FRFamide precursor (for details, see Table 1), as well as known neuropeptides derived from other precursors. Among the known peptides detected in the S-cluster neurons were sensorins $\mathrm{A}$ and $\mathrm{B}$, peptides that serve as markers for sensory neurons in Aplysia (Walters et al., 2004).

To further analyze the expression of the RFamide peptides in the S-cluster neurons, we performed MALDI MS on S1 and S2 neurons that had been proteolytically dissociated and grown at low density in cell culture. Unlike freshly isolated neurons, such cultured neurons are free of synaptic terminals from other neurons and thus ensure that the detected peptides are truly expressed by the neuron being analyzed. Representative mass spectra of two S1 and two S2 neurons are shown in Figure 4. 
A
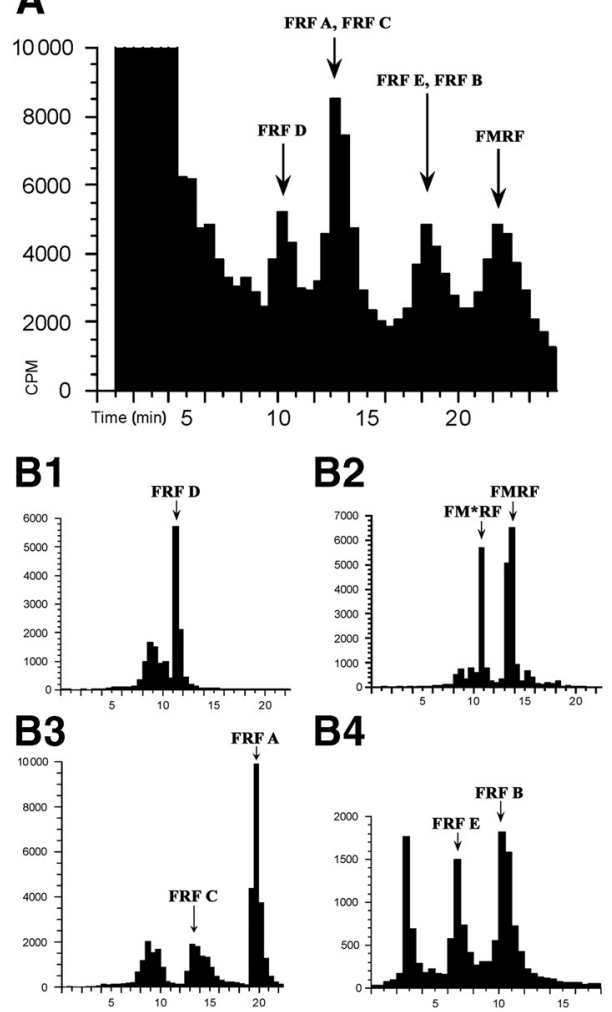

B4

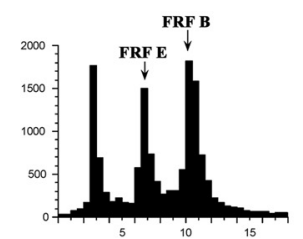

C
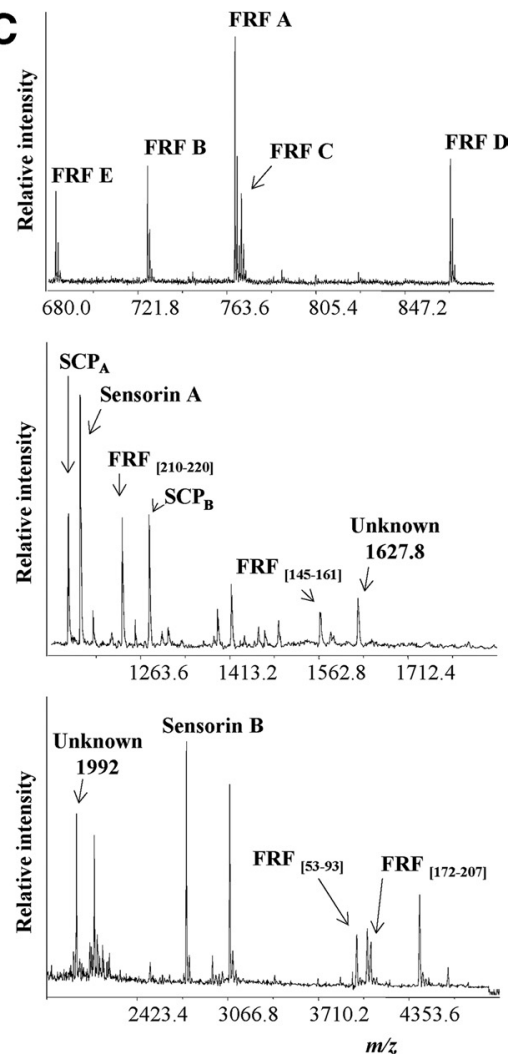

Figure 3. Synthesis of the FRFamide and FMRFamide peptides in buccal sensory neurons. $\boldsymbol{A}, \boldsymbol{B}$, Radiolabeling and HPLC. Metabolic labeling of the RFamide peptides was accomplished by incubation of buccal ganglia with tritiated phenylalanine. The radiolabeled peptides were extracted from isolated S-clusters and separated by HPLC. The retention times of the radiolabeled peptides (peaks in the count distribution, shown in black) were compared with those of added synthetic RFamides (labeled arrows). $\boldsymbol{A}$, The first stage of HPLC. B1-B4, The peaks from the first stage were rechromatographed using different columns and counterions that were designed to separate the different RFamides. Radiolabeled peaks corresponding to all five amidated FRFamides A-E can be seen. In $\boldsymbol{B 2}$, two peaks of radioactivity can be seen, one corresponding to FMRFamide (FMRF) and the other to FMRFamide with an oxidized methionine (FM*RF). C, MALDI MS. Representative MALDI mass spectrum (divided into 3 sections) of a single freshly isolated S-cluster neuron exhibits peaks corresponding to all five amidated FRFamides A-E (top section), as well as linker peptides derived from the FRFamide precursor and other known and putative peptides.

Table 1. MALDI MS detection of peptides predicted from the FRFamide precursor in a single freshly isolated buccal $S$-cluster neuron, whose mass spectrum is shown in Figure $3 C$

\begin{tabular}{llccc}
\hline Peptide name & Predicted peptides & $\begin{array}{l}\text { Calculated mass } \\
(\mathrm{M}+\mathrm{H})^{a}\end{array}$ & $\begin{array}{l}\text { Observed mass } \\
(\mathrm{M}+\mathrm{H})\end{array}$ & $\begin{array}{l}\text { Mass error } \\
(\mathrm{PPM})\end{array}$ \\
\hline FRF linker 1 & $\mathrm{S}[53]-\mathrm{D}[93]$ & 3983.32 & 3983.16 & 40 \\
FRF $_{\mathrm{C}}{ }^{b}$ & $\mathrm{~S}[95]-\mathrm{F}[101]-\mathrm{NH}_{2}$ & 769.420 & 769.416 & 5 \\
FRF $_{\mathrm{D}}$ & $\mathrm{G}[105]-\mathrm{F}[112]-\mathrm{NH}_{2}$ & 867.468 & 867.472 & 5 \\
FRF $_{\mathrm{B}}{ }^{b}$ & $\mathrm{G}[116]-\mathrm{F}[121]-\mathrm{NH}_{2}$ & 725.393 & 725.390 & 4 \\
FRF $_{\mathrm{A}}{ }^{b}$ & $\mathrm{G}[125]-\mathrm{F}[131]-\mathrm{NH}_{2}$ & 766.420 & 766.421 & 1 \\
FRF linker 2 & $\mathrm{G}[135-141]-\mathrm{NH}_{2}$ & & & \\
FRF $_{\mathrm{E}}$ & $\mathrm{G}[145]-\mathrm{V}[161]$ & 1564.713 & 1564.699 & 9 \\
FRF linker 3 & $\mathrm{T}[164]-\mathrm{F}[168]-\mathrm{NH}_{2}$ & 682.388 & 682.385 & 4 \\
FRF linker 4 & $\mathrm{S}[172]-\mathrm{S}[207]$ & 4083.35 & 4083.23 & 29 \\
\hline
\end{tabular}

${ }^{a}$ Masses of protonated peptide ions of $<2000$ are listed as monoisotopic; for ions $>2000$, masses are listed as average.

${ }^{b}$ Previously reported peptides.

PPM, Assignment mass errors are shown in parts per million.

Altogether, in 14 successfully analyzed S1 neurons, we detected FMRFamide alone in four neurons (Fig. 4, S1 neuron 2), FMRFamide together with the five FRFamides A-E, but at very low intensity, in four neurons, and FMRFamide with the FRFamides at approximately comparable intensity in six neurons (e.g., S1 neuron 1); we did not detect the FRFamides without FMRFamide. In seven successfully analyzed S2 neurons, conversely, we did not detect FMRFamide without the FRFamides; we detected FMRFamide with the FRFamides in one neuron (S2 neuron 1) and the FRFamides alone in six neurons (e.g., S2 neuron 2). Thus, the MALDI MS generally confirmed the results of the in situ hybridization and immunostaining. It appears that most neurons in both the S1 and S2 clusters express RFamides, and some neurons, in both clusters, coexpress both the FRFamides and FMRFamide. On the whole, however, the neurons in the S1 cluster tend to preferentially express FMRFamide, and those in the $\mathrm{S} 2$ cluster the FRFamides.

\section{FRFamide and FMRFamide actions in the CNS}

The foregoing results showed that the peptides derived from the FRFamide and FMRFamide precursors are present in many neurons in the buccal ganglion, the principal ganglion of the feeding system. This raised the possibility that the peptides may participate in the generation or regulation of feeding behavior. To examine this possibility, we studied the effects of synthetic FRFamide and FMRFamide peptides on the motor programs generated by the feeding central pattern generator (CPG) that resides in the buccal ganglion (Susswein and Byrne, 1988; Cropper et al., 2004; Baxter and Byrne, 2006).

The buccal feeding CPG of Aplysia can generate three major types of feeding motor programs: ingestive, egestive, and intermediate (Morton and Chiel, 1993a,b; Nargeot et al., 1999; Lechner et al., 2000; Morgan et al., 2002). Based on a combination of behavioral studies, chronic recordings in free-feeding animals, and intracellular studies in the isolated nervous system, criteria defining the three types of programs have been established, and we used these criteria here (see Materials and Methods). Briefly, in ingestive programs, the radula closer motor neurons B8 fire strongly during the radula retraction phase of the program to close the radula during retraction so as to bring food into the mouth of the animal. In egestive programs, conversely, the motor neurons B8 fire strongly during the protraction phase to close the radula during protraction so as to expel inedible material out of the mouth. When the B8 firing frequencies measured in the two phases of each program are plotted against each other in a two-dimensional plane, the strong firing in retraction or protraction defines regions in which the ingestive and egestive programs reside, as indicated by the curved outlines in Figure $5 B$. When the B8 firing frequencies fall outside of these regions, the programs are classified as intermediate.

In this series of experiments, we elicited the feeding motor programs in the isolated nervous system by intracellular stimulation of neuron CBI-2. CBI-2 is a command-like neuron that fires in response to food stimuli in vivo and its firing elicits feeding motor programs in the isolated nervous system and feeding 
movements in semi-intact preparations (Rosen et al., 1991; Morgan et al., 2002; Jing and Weiss 2005). The type of motor program that CBI-2 elicits depends on the state of the feeding CPG (Proekt et al., $2004,2007,2008)$. In a rested preparation, CBI-2 stimulation at first elicits intermediate programs, but, when CBI-2 is stimulated so as to elicit programs at frequent intervals, the programs become ingestive. In contrast, stimulation of the esophageal nerve, which contains afferent sensory axons from the digestive tract, elicits egestive motor programs. When CBI-2 is stimulated after a series of egestive programs elicited by stimulation of the esophageal nerve, however, the CBI-2 stimulation at first likewise elicits egestive programs.

In these experiments, we stimulated CBI-2 at frequent intervals so as to elicit a regular series of motor programs. To produce programs with stable characteristics, particularly with stable B8 firing during protraction and retraction, we repetitively stimulated CBI-2 for 10-15 min, until the programs became ingestive and at least three stable ingestive programs had been produced. To show quantitatively that these three control programs immediately before peptide applications are indeed stable, we selected one experiment from each of four sets of peptide experiments (shown in Fig. 5A1-A4) by random drawing and calculated B8 firing frequency during protraction and retraction. On average, B8 activity during protraction for first, second, and third programs were, respectively, as follows (in $\mathrm{Hz}$ ): $1.47 \pm 0.24$, $1.62 \pm 0.34$, and $1.65 \pm 0.34$. These firing frequencies were not significantly different from each other $\left(F_{(2,6)}=1.03, p=0.41\right.$, $n=4)$. Similarly, B8 activity during retraction for first, second, and third programs were, respectively, as follows (in $\mathrm{Hz}$ ): $7.28 \pm$ $0.82,7.67 \pm 0.88$, and $7.88 \pm 0.94$. These firing frequencies were not significantly different from each other $\left(F_{(2,6)}=1.44, p=\right.$ $0.31, n=4)$.

We then superfused either FRFamide A or FMRFamide or a combination of both peptides. Separately, FRFamide A and FMRFamide both exerted strong, but distinct, actions on the motor programs. Figure 5, $A 1$ and $A 2$, shows representative programs in the absence (left) and presence (middle) of the peptides, and $B 1$ and $B 2$ shows the corresponding plots of the B8 firing frequencies measured from programs in the absence (circles) and presence (triangles) of the peptides in multiple experiments. Both peptides produced programs that were less ingestive, but they did so in different ways. FRFamide A decreased the firing of B8 during the retraction phase of the programs, whereas FMRFamide increased it during the protraction phase. Both peptides thus shifted the programs from the ingestive region of the plane of B8 firing frequencies to the intermediate region but to different parts of it: FRFamide A to the region of low B8 firing frequency in both protraction and retraction (Fig. 5B1), and FMRFamide to the region of high $\mathrm{B} 8$ firing frequency in both protraction and retraction (Fig. 5B2). Neither peptide alone produced fully egestive programs. When both peptides were applied together, however, the combination of their effects was able to convert the ingestive programs into fully egestive programs, with high B8 firing frequency in protraction but low in retraction (Fig. $5 A 3, A 4, B 3, B 4$ ).

\section{S2 Neurons}
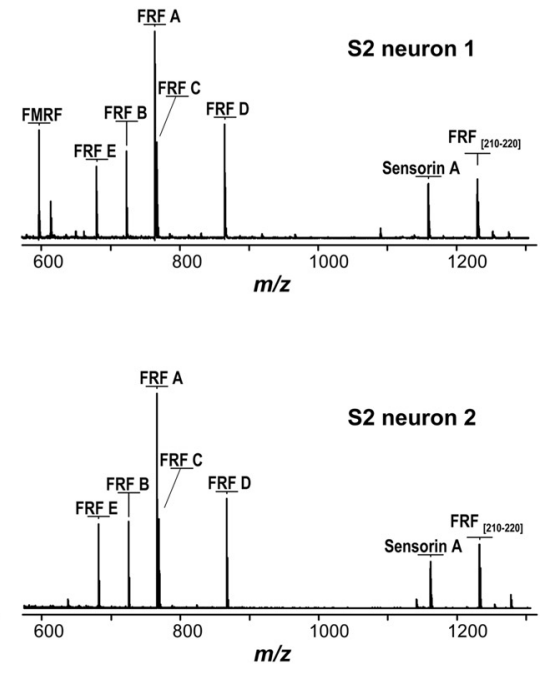

S1 neuron 2

$m / z$

S1 and S2 neurons. Some S1 and S2 neurons contained both FMRFamide and the five FRFamides $A-E$, as well as other peptides ( $S 1$ neuron 1 and $S 2$ neuron 1). However, FMRFamide alone was found only in S1 neurons (S1 neuron 2), and the FRFamides alone was found only in S2 neurons (S2 neuron 2).

The effects of the peptides were fully reversible on washout (Fig. $5 A 1-A 4$, right). Figure $5 C 1-C 4$ shows group data of the effects of $10^{-6}$ M FRF A (C1: B8 during protraction, $F_{(2,16)}=3.38, p=0.06$; B8 during retraction, $\left.F_{(2,16)}=21.36, p<0.0001 ; n=9\right), 10^{-6} \mathrm{M}$ FMRF (C2: B8 during protraction, $F_{(2,16)}=23.23, p<0.0001$; B8 during retraction, $\left.F_{(2,16)}=2.51, p=0.11, n=9\right), 10^{-6} \mathrm{M} \mathrm{FMRF}+$ $10^{-6}$ M FRF A (C3: B8 during protraction, $F_{(2,10)}=56.26, p<$ 0.0001; B8 during retraction, $\left.F_{(2,10)}=41.45, p<0.0001 ; n=6\right)$, and $10^{-6} \mathrm{M} \mathrm{FMRF}+3 \times 10^{-6} \mathrm{M}$ FRF A (C4: B8 during protraction, $F_{(2,8)}=72.94, p<0.0001$; B8 during retraction, $F_{(2,8)}=$ $16.66, p<0.01 ; n=5)$. Typically, the peptides were perfused for $10-15 \mathrm{~min}$ and were washed for up to $50 \mathrm{~min}$. Notably, despite the long duration of the experiment $(>1 \mathrm{~h})$, after washout, B8 firing frequency during protraction and retraction were not statistically different from controls (Fig. 5C1-C4), thus indicating a complete recovery. Furthermore, FRF A and FMRF actions differed from each other. Specifically, FRF A affected B8 firing frequency during retraction, whereas FMRF affected B8 during protraction. Together, the motor programs elicited by our stimulation paradigms were stable in the absence of peptides and did not display signs of a systematic drift.

In converting the CBI-2-elicited ingestive programs into egestive programs, the joint superfusion of FRFamide A and FMRFamide had similar effects to those of repetitive stimulation of the esophageal nerve (Morgan et al., 2002; Proekt et al., 2004). We therefore sought to determine whether RFamide peptides were present in the esophageal nerve using MALDI MS of esophageal nerve extracts. Indeed, we detected both FMRFamide and the five FRFamides A-E in these extracts (Fig. 6). These data are consistent, therefore, with the possibility that the ability of the esophageal nerve stimulation to convert CBI-2-elicited ingestive programs into egestive programs may in part be mediated by the RFamide peptides.

\section{RFamide release in the periphery}

The evidence so far showed that the FRFamide and FMRFamide peptides are present in many neurons and that exogenous application of the peptides has physiological effects. However, it did 

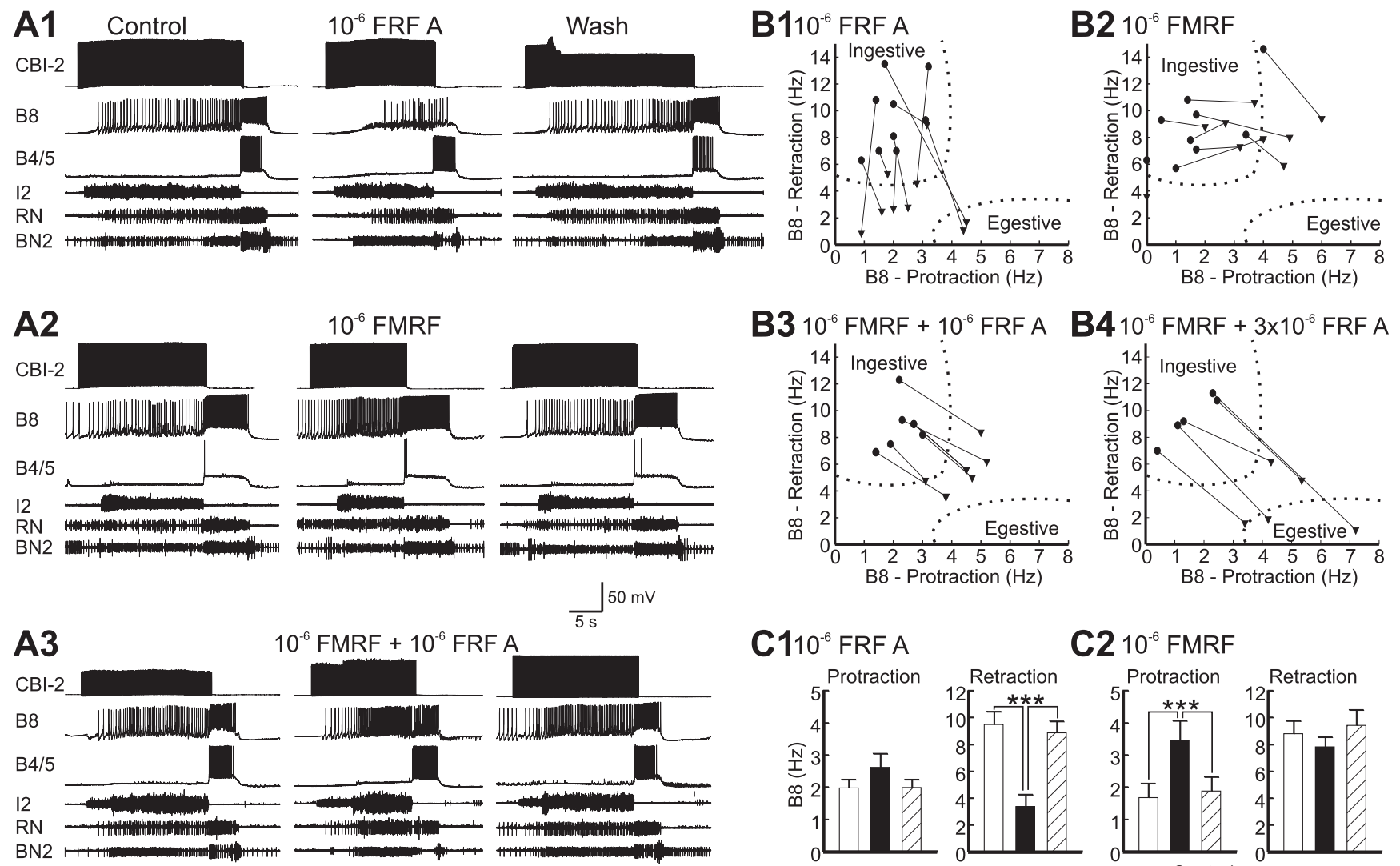

B3
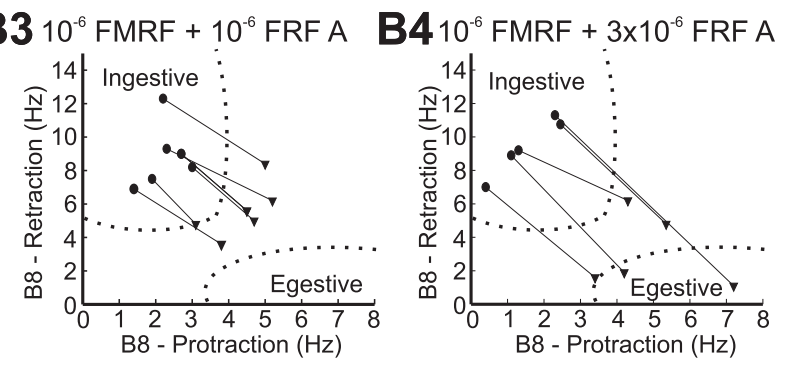

C1
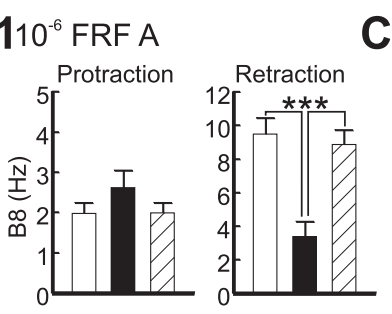

C2 $10^{-6} \mathrm{FMRF}$
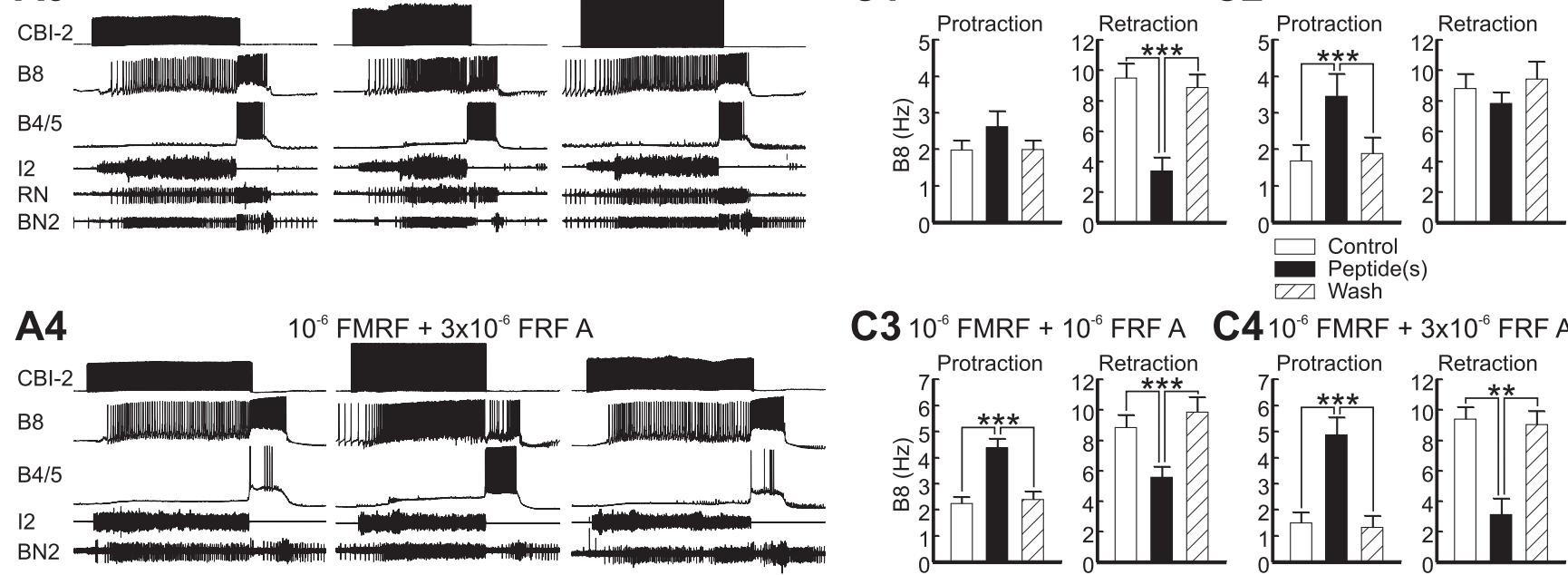

Figure 5. Effects of FRFamide and FMRFamide on feeding motor programs. A1-A4, Feeding motor programs elicited by intracellular stimulation of CBI-2 in the absence (left), superfused presence (middle), and after washout (right) of the indicated concentrations (in molar) of synthetic FRFamide A and FMRFamide. The radula protraction phase of the motor programs was identified by the activity in the extracellular recording from the I2 nerve (I2), the radula retraction phase by the intracellularly recorded depolarization of neuron B4/5 and the activity in the extracellular recording from buccal nerve 2 (BN2), and radula closure by the intracellularly recording firing of the radula closer motor neuron $\mathrm{B} 8$ and its reflection in the extracellular recording from the radula nerve (RN) (see Materials and Methods). B1-B4, Analysis of individual experiments corresponding to A1-A4. Plotted is the firing frequency of motor neuron B8 during the retraction phase ( $y$-axis) against its firing frequency during the protraction phase ( $x$-axis), in the absence (circle) and presence (triangle) of the peptide(s) in each experiment. (1-C4, Group data showing the effects on B8 activity during protraction and retraction by the peptides corresponding to examples shown in $\mathbf{A 1 - A 4}$, respectively. Bonferroni's post hoc tests: ${ }^{* *} p<0.01$; ${ }^{* * *} p<0.001$. Error bars indicate SEM.

not show that the endogenous peptides are in fact released. To show this, we used a neuromuscular preparation that has been used previously to measure the release of several other families of neuropeptides in the Aplysia feeding system (Vilim et al., 1996a,b, 2000). This preparation is based on the ARC muscle (Cohen et al., 1978), the best studied of the buccal-mass muscles that perform the feeding movements driven by the buccal feeding motor programs. The method uses RIA to measure the amount of peptide appearing in drops of perfusate of the muscle, having been released from neuronal terminals and processes in the muscle, in response to stimulation of motor neurons B15 and B16 of the muscle or of buccal nerve 3 , the nerve that carries the innervation, both motor and sensory, between the buccal ganglion and the muscle. At the same time, the muscle is set up so that it continues to contract in response to the stimulation.

We did not attempt to distinguish in these experiments between the release of the FRFamides and FMRFamide. In the RIA, we used a rabbit antibody that was raised against FRFamide A but that detected both RFamides, albeit with a 10-fold greater sensitivity to FRFamides than FMRFamide. MALDI MS was not performed on the releasate because this method is not very useful for quantification of peptides released under different conditions. Given that both the FRFamides and FMRFamide are present in the ARC muscle (see below), the RIA in these experiments was thus most likely detecting the release of both RFamides. In the absence of a more selective detection method that would make it worthwhile to differentiate between FRFamide- and FMRFamidecontaining neurons innervating the muscle, we primarily used a stimulation method, namely stimulation of the entire nerve 3 , that was likely to release both RFamides.

As can be seen in Figure 7A1, when nerve 3 was stimulated (black bars), there was a large increase in the amount of RFamide detected in the perfusate of the ARC muscle. This increase in RFamide was reversibly abolished when calcium in the solution 


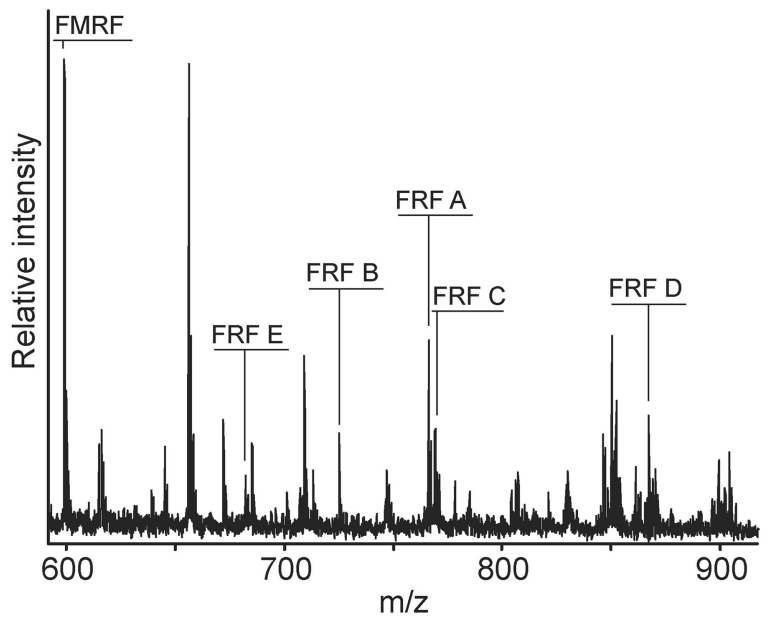

Figure 6. MALDI mass spectrum of esophageal nerve extract shows peaks corresponding to FMRFamide as well as the five FRFamides, i.e., FRF A-E. m/z, Mass-to-charge ratio.

perfusing the muscle was replaced with magnesium, demonstrating that the release of RFamide is calcium dependent as is typical for the release of neuropeptides (Vilim et al., 1996a, 2000; Strand, 1999). Figure $7 A 2$ shows the combined results from six experiments; the reduction in RFamide release on removal of calcium was repeatedly observed and was statistically significant $(p<0.001)$.

What was the source of the released RFamide? As with all other families of neuropeptides studied in the system, the source was not the muscle cells themselves but rather neuronal processes innervating the muscle (see Fig. 8). However, these were not processes of either of the ARC motor neurons B15 or B16: although these do contain peptides of other families, they do not contain the RFamides (see below). The most likely hypothesis was that some of the buccal sensory neurons, the major neuronal type expressing the RFamides in the buccal ganglion, innervate the ARC muscle and, during stimulation, release the RFamide from their processes there. There is indeed some anatomical and electrophysiological evidence that buccal sensory neurons innervate buccal-mass muscles, including the ARC muscle (see Discussion). We adopted this as our working hypothesis.

The primary neurotransmitter of the ARC motor neurons B15 and $\mathrm{B} 16$ is acetylcholine (ACh), the release and action of which is completely responsible for producing the contractions of the muscle; the contractions are completely blocked by the cholinergic antagonist hexamethonium (Cohen et al., 1978). In the previous studies in the ARC release preparation that measured release of the peptide cotransmitters of the ARC motor neurons, it was found that, although hexamethonium abolished the contractions, it had no effect at all on the release of those peptides (Vilim et al., 1996a, 2000). In contrast, we observed that the release of the RFamides was considerably reduced, although not abolished, by hexamethonium (Fig. 7B1). The block was reversible, repeatable, and statistically significant (Fig. 7B2) $(p<0.05)$.

The effect of hexamethonium on the RFamide release was surprising, because the axons in buccal nerve 3 , including those of the putative RFamide-containing sensory neurons, continued to be stimulated in the same way as before in the presence of the hexamethonium. It appeared that there was some factor associated with the contractions of the muscle that enhanced RFamide release, which therefore diminished when the contractions were blocked by hexamethonium. One possibility was that the putative RFamide-containing sensory neurons are mechanoafferents and release the RFamide, in addition to any central release, peripher- ally in the muscle itself in response to the mechanical stimuli that they sense during contraction.

To investigate this possibility, we elicited contractions of the ARC muscle in a more selective manner, by intracellularly stimulating just the ARC motor neuron B15. As already mentioned, motor neuron B15 does not contain, and so cannot itself release, RFamide. Nevertheless, as Figure 7C1 shows, the stimulation of B15 still elicited a clear increase in the amount of RFamide appearing in the perfusate of the muscle. To be sure, this increase was considerably smaller than that elicited by the stimulation of the entire buccal nerve 3 , as is shown at the end of the experiment in Figure 7C1 for comparison. However, the B15-elicited increase, unlike the nerve 3-elicited increase, was almost completely blocked by hexamethonium (Fig. 7C2) $(p<0.01)$.

Altogether, we interpreted these results to mean that, indeed, there were two components of the nerve 3-elicited RFamide release that reflected two mechanisms by which the stimulation of the nerve acted on the putative RFamidecontaining mechanoafferent sensory neurons innervating the ARC muscle. First, the stimulation directly fired the axons of the mechanoafferent neurons coursing through nerve 3 to release the RFamide from their terminal processes in the muscle, in a hexamethonium-insensitive manner. Second, the stimulation also fired the axons of the ARC motor neurons B15 and B16 in nerve 3, producing a hexamethonium-sensitive contraction of the muscle that was then locally sensed by the processes of the mechanoafferent neurons to release RFamide. Both components of release were seen in Figure 7, $A$ and $B$, and only the second component was seen in Figure $7 C$.

\section{Both FRFamides and FMRFamide are present in the ARC muscle but not in the ARC motor neurons}

In our in situ hybridization and immunofluorescence mapping of the buccal ganglion in Figure 2, we found no FRFamide in the ventral motor neuron cluster in which the somata of the ARC motor neurons B15 and B16 are located. We did find FMRFamide in some of the motor neuron somata; however, a previous study using radiolabeling and HPLC showed that, although FMRFamide is indeed synthesized in some motor neurons, it is not synthesized in motor neuron B15 or B16 (Church and Lloyd, 1991). To provide additional evidence that the RFamide released in the ARC muscle did not originate from the motor neurons of the muscle, we performed double-labeled immunostaining of the muscle with the nonspecific RFamide antibody used for the release RIA and specific antibodies to two neuropeptide families known to be present in the motor neurons, specifically the small cardioactive peptides (SCPs) in B15 (Cropper et al., 1987a; Vilim et al., 1996a,b) and the myomodulins in B16 (Cropper et al., 1987b; Vilim et al., 2000). Figure 8 A2 shows the SCP-immunostained processes of B15, and Figure $8 B 2$ shows (in a different muscle) the myomodulin-immunostained processes of B16. The corresponding RFamide staining is shown in Figure $8, A 1$ and $B 1$, respectively. Clearly, the RFamide is contained in a set of processes quite different from those of B15 and B16. According to our hypothesis, these are the processes of the buccal sensory neurons that innervate the muscle.

The nonspecific RFamide antibody used in Figures 7 and 8 did not tell us whether the RFamide present and released in the ARC muscle was FRFamide, FMRFamide, or both. However, there was other evidence that both the FRFamides and FMRFamide are in fact present. Using depression of the motor neuron-elicited contractions of the ARC muscle (see below) as a bioassay in combination with HPLC purification, Cropper et al. (1994) isolated and 
A1

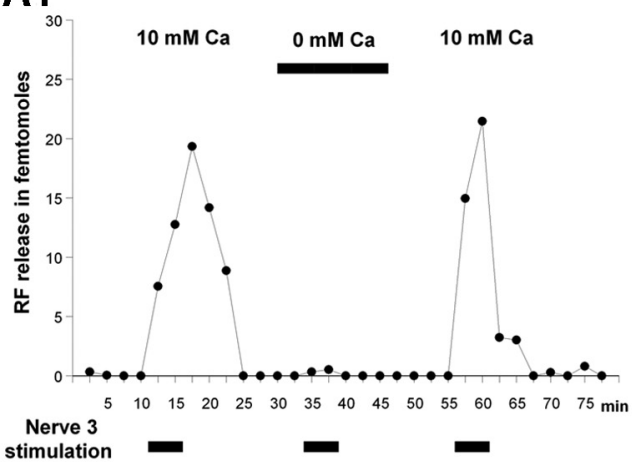

B1
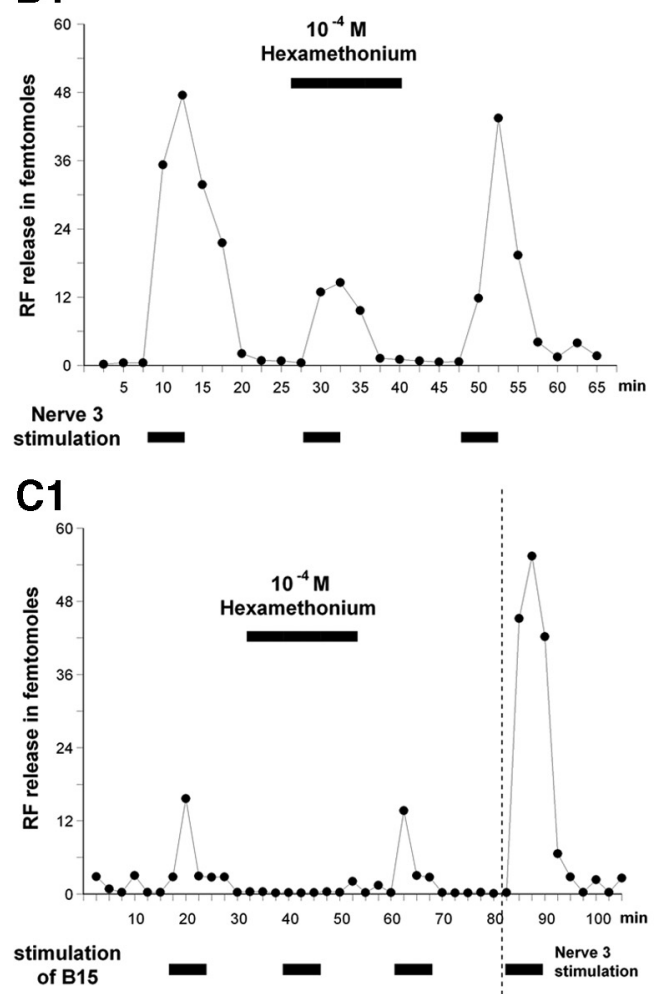

A2

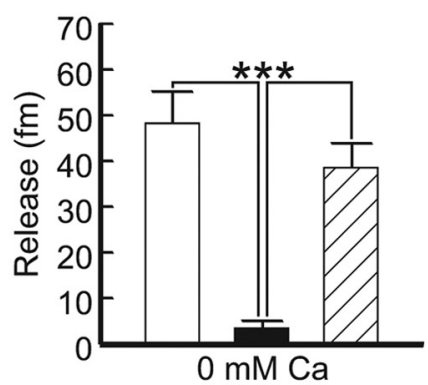

\section{B2}

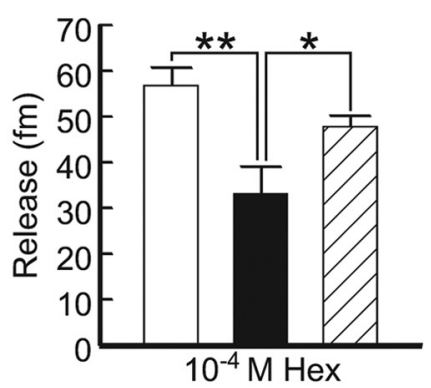

C2

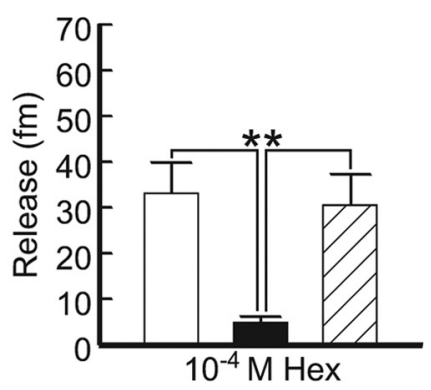

Figure 7. RFamide release in the ARC muscle. The RFamide content of successive drops of perfusate of the ARC muscle was measured with RIA. A, Calcium dependence of RFamide release. $\boldsymbol{A} \mathbf{1}$, Buccal nerve 3 was extracellularly stimulated at $20 \mathrm{~Hz}$ for $3.5 \mathrm{~s}$ every $7 \mathrm{~s}$ for $5 \mathrm{~min}$, three times as shown by the black bars. For the middle period of stimulation, the calcium in the solution perfusing the muscle was replaced with magnesium. $\boldsymbol{A 2}$, Group data of RFamide measured in the stimulation period before (48.5 \pm 6.67 ), during ( $3.5 \pm 1.53$ ), and after ( $38.83 \pm 5.08$ ) perfusion of calcium-free ASW (means $\pm S E M ; n=6$ ). B, Block of RFamide release by hexamethonium (Hex). As in $A$, except that $10^{-4} \mathrm{M}$ hexamethonium was added to the solution perfusing the muscle for the middle period of stimulation. B2, Group data of RFamide measured in the stimulation period before $(57.0 \pm 3.65)$, during (33.2 \pm 5.81 ), and after ( $48.0 \pm 2.21$ ) perfusion of hexamethonium containing ASW (means \pm SEM; $n=5$ ). C, Block by hexamethonium of RFamide release elicited by stimulation of the ARC motor neuron B15. As in $\boldsymbol{B}$ except with intracellular stimulation of motor neuron B15 instead of the buccal nerve 3 stimulation. However, the fourth black bar in $\mathbf{C}$ indicates a period of nerve 3 stimulation added for comparison. (2, Group data of RFamide measured in the stimulation period before (33.25 \pm 6.67), during $(5.0 \pm 1.12)$, and after (30.75 \pm 6.61$)$ perfusion of hexamethonium containing ASW (means \pm SEM; $n=4$ ). In A2, B2, and C, results of statistical analysis of group data via $t$ test is indicated as follows: ${ }^{*} p<0.05 ;{ }^{* *} p<0.01 ;{ }^{* * *} p<0.001$.

sequenced the FRFamides A-C from extracts of the ARC muscle. Here, we used the same approach to isolate and sequence FMRFamide from the muscle. Figure $9 A-D$ shows four sequential stages of HPLC purification using different conditions. Inhibition (depression) of motor neuron-elicited ARC muscle contractions was used as a bioassay. In Figure 9, $A$ and $B$, the percentage inhibition of contractions is plotted as a function of fraction number. The fraction marked with the asterisk at each stage was isolated and used in the following stage. In Figure 9, $C$ and $D$, the bioactive peptide was of sufficient purity to appear as a single absorbance peak, marked with the asterisk. The asterisked peak in Figure 9D was lyophylized and sequenced using the Edman method. The result was as follows: cycle $1, \mathrm{~F}$; cycle $2, \mathrm{M}$; cycle 3 , R; cycle 4, F. Thus, the ARC muscle contains not only the FRFamides but also FMRFamide.

FRFamide and FMRFamide actions on ARC neuromuscular function

The foregoing results demonstrated the presence of both the FRFamides and FMRFamide in the ARC muscle and strongly suggested that the peptides may be released not only by experimental manipulations but during physiologically relevant activity to play some role in the functional operation of the muscle. We therefore sought to determine the actions of the FRFamides and FMRFamide on the electrophysiology of the ARC neuromuscular junctions and the contractions of the muscle.

The actions of FMRFamide have not been reported previously (see below for more methodological details). When applied to ARC neuromuscular preparations in which contractions of the muscle were elicited by regular bursts of spikes fired by the motor neurons B15 and B16, FMRFamide depressed the amplitude of the contractions (Fig. 10A) in a dosedependent manner with a threshold of $\sim 10^{-10} \mathrm{M}$ (Fig. 10B). B15- and B16elicited contractions were depressed to approximately the same extent (Fig. 10A). Although the contractions were strongly depressed, the compound EJPs underlying the contractions were little altered, exhibiting some reduction in depolarization only during the initial summation of the compound EJP (Fig. 10C1,C2). FMRFamide did not obviously change the resting membrane potential of the ARC muscle fibers (Fig. 10C1).

The actions of the FRFamides $\mathrm{A}-\mathrm{C}$ in the ARC neuromuscular preparation have been described previously (Cropper et al., 1994). Here we therefore sought to determine the actions of the newly identified FRFamides D and $\mathrm{E}$ and generally to compare the effects of the FRFamides with those of FMRFamide. We found that the actions of the FRFamides D and E were almost identical to the actions described previously for the FRFamides A-C, which differed in a number of important respects from those of FMRFamide. When applied to the ARC neuromuscular preparations, FRFamides D and E, too, depressed the contractions in a dose-dependent manner (Fig. 11A). However, like the FRFamides A-C but unlike FMRFamide, at any 


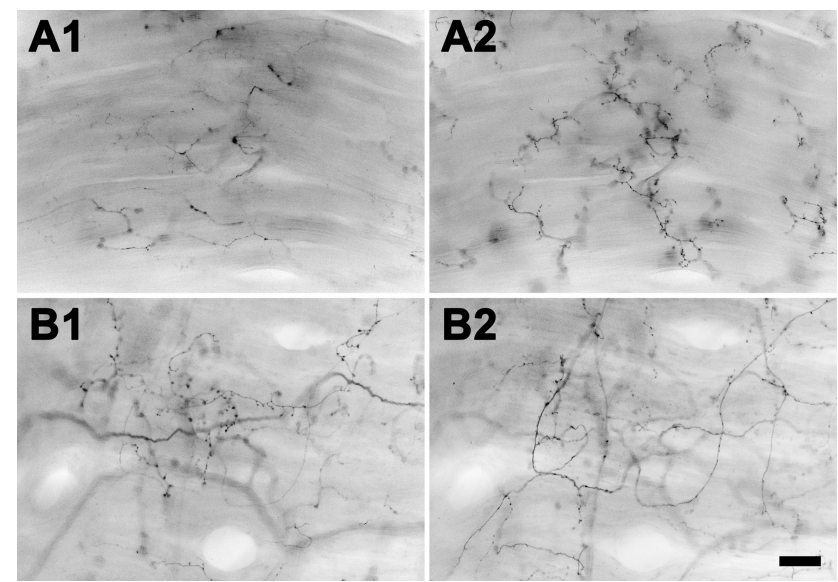

Figure 8. RFamides are not present in the $A R C$ motor neurons. ARC muscle immunostaining with the nonspecific rabbit RFamide antibody and rat antibodies to small cardioactive peptide (present in motor neuron B15 processes in the muscle) and myomodulin (present in motor neuron B16 processes). $\boldsymbol{A}$, Double labeling of the same field for RFamide (A1; rhodamine) and SCP ( $\boldsymbol{A} 2$; fluorescein). $\boldsymbol{B}$, Double labeling of the same field for RFamide ( $\boldsymbol{B} 1$; rhodamine) and myomodulin (B2; fluorescein). Note that the RFamide immunostaining pattern does not coincide with that of either ARC motor neuron marker peptide. Negative images are shown for enhanced visibility. Scale bar, $100 \mu \mathrm{m}$.

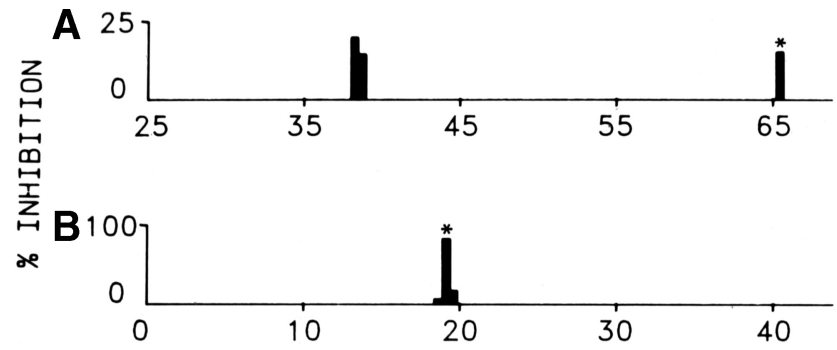

\section{C}

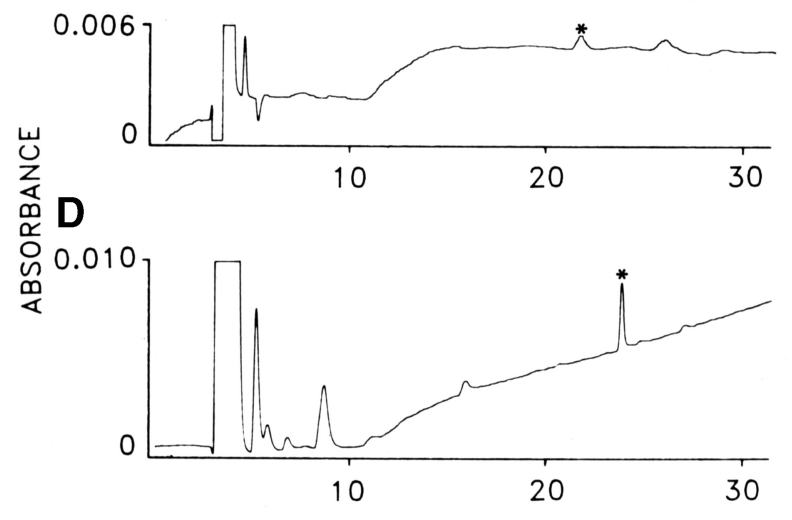

ELUTION TIME (MIN)

Figure 9. FMRFamide is present in the ARC muscle. Purification of FMRFamide from ARC muscle extracts based on bioassay in the ARC neuromuscular preparation of fractions from four sequential stages of HPLC with different conditions. The peak marked with the asterisk in each of $\boldsymbol{A}-\boldsymbol{C}$ was isolated and used in the following stage. $\boldsymbol{A}, \boldsymbol{B}$, Percentage inhibition (depression) of motor neuron-elicited ARC muscle contractions produced by HPLC fractions eluting at the times (in minutes) shown on the $x$-axis. C, D, Optical absorbance at $215 \mathrm{~nm}$ of the last two HPLC runs. The peak marked with the asterisk in $\boldsymbol{D}$ was subjected to Edman sequencing and had the sequence (with picomoles detected) $F(55), M(49), R(17), F(14)$.

given concentration, they depressed B16-elicited contractions to a greater extent than B15-elicited contractions (Fig. 11A,B2). Furthermore, all of the FRFamides depressed the contractions much less potently than did FMRFamide. Figure 11 B1 shows the
A

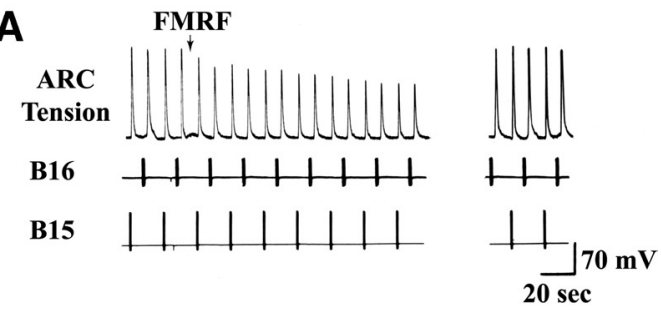

B

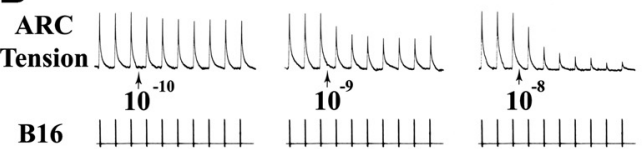

B16

$\underset{\min }{50} \mathrm{mV}$

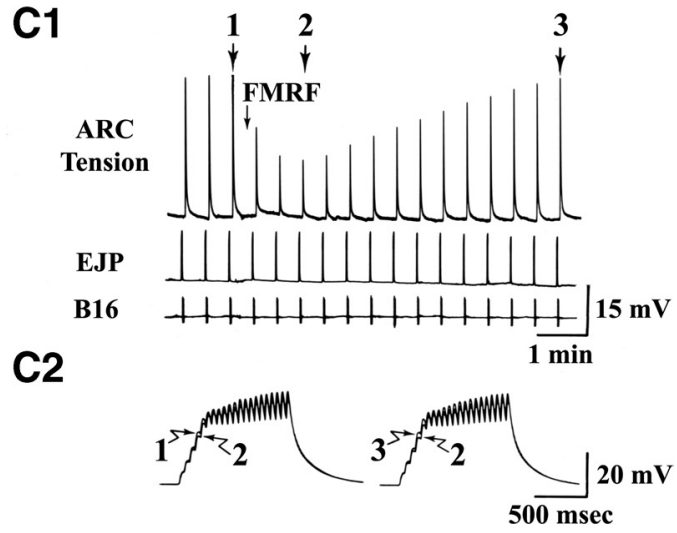

Figure 10. Effects of FMRFamide on ARC muscle contractions and EJPs. $A$, Depression of contractions elicited by alternating bursts of spikes of the two motor neurons B15 and B16 by superfused application of $10^{-9} \mathrm{M}$ FMRFamide. The panel at right shows washout. $\boldsymbol{B}$, Dose dependence of the depression of the B16-elicited contractions by progressively increasing concentrations of FMRFamide, indicated in molar. C1, Effect of transient application of $10^{-8} \mathrm{M}$ FMRFamide on the B16-elicited contractions and the underlying compound EJPs. Representative EJPs before the FMRFamide application (1), at the peak of the depression of contractions (2), and after recovery of the contractions (3) are expanded and superimposed in $\mathbf{C}$.

dose-response relations for the FRFamides C-E (FRFamides A and $B$ were found previously to be equipotent with FRFamide C), and Figure $11 B 2$ compares the corresponding $K_{\mathrm{D}}$ values. In the only significant difference that we found between the effects of the FRFamides, FRFamide E was approximately threefold less potent than the other FRFamides. However, the threshold effects of even the more potent FRFamides occurred only $\sim 10^{-8}$ M, 100-fold higher than with FMRFamide. Finally, the FRFamides D and E, like the FRFamides A-C but unlike FMRFamide, hyperpolarized the resting potential of the ARC muscle fibers and considerably reduced the amplitude of the compound EJPs underlying the contractions (Fig. 11C1,C2).

\section{Presynaptic versus postsynaptic actions of the FRFamides and FMRFamide}

Depression of ARC muscle contractions with minimal alteration of the resting potential of the muscle fibers or of the compound EJPs has been described previously and analyzed with the buccalins (Cropper et al., 1988, 1990; Miller et al., 1993a; Vilim et al., 1994), a family of peptides released as cotransmitters from both motor neurons B15 and B16 (Vilim et al., 1996a,b, 2000), as well as with some of the myomodulins released as cotransmitters from motor neuron B16 (Vilim et al., 2000; Orekhova et al., 2003). Depression of the contractions with hyperpolarization of the 
A
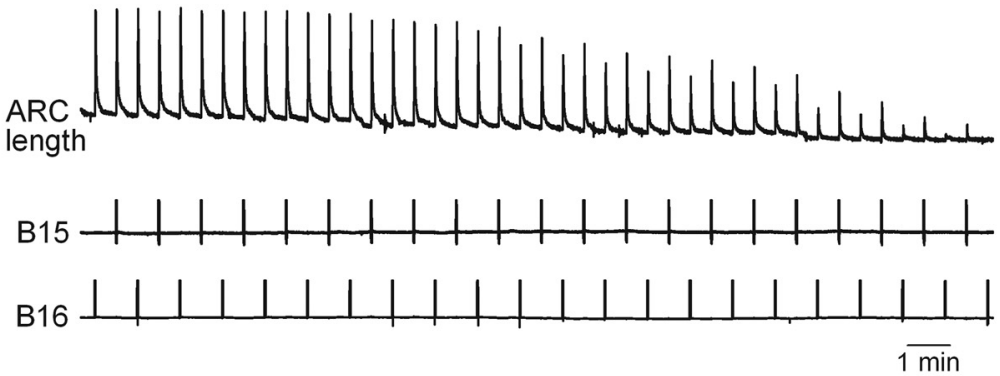

B1
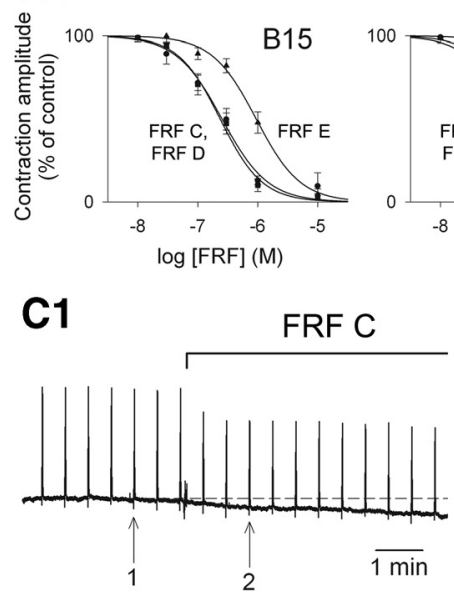

FRF D

$300 \mathrm{nM} \quad 1 \mu \mathrm{M}$

\section{B2}
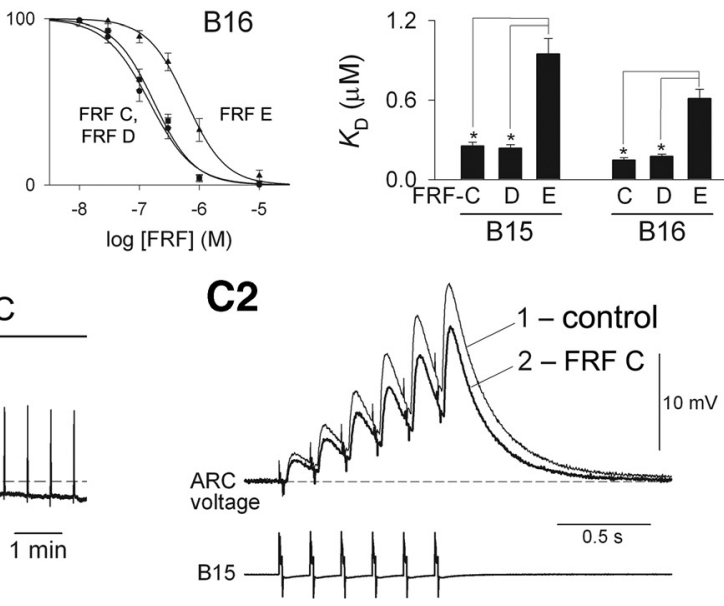

C2

Figure 11. Effects of the FRFamides on ARC muscle contractions and EJPs. A, Depression of contractions elicited by alternating bursts of spikes of the two motor neurons B15 and B16 by superfused application of increasing concentrations of FRFamide $D$. B1, Dose-response relations for the depression of the B15- and B16-elicited contraction amplitude by FRFamides C (circles), D (squares), and $\mathrm{E}$ (triangles). Each symbol is the mean $\pm \mathrm{SE}$ of measurements from three to seven (in most cases 6 ) experiments, normalized to the control contraction amplitude in each experiment. The smooth curves are best fits of the sigmoid function $\%$ contraction amplitude $=100 /\left(1+\left\{[\mathrm{FRF}] / K_{\mathrm{D}}\right\}^{a}\right)$, where [FRF] is the FRFamide concentration, $K_{\mathrm{D}}$ is the concentration at halfmaximal depression, and $a$ is a constant. $\boldsymbol{B 2}$, Comparison of the $K_{D}$ values \pm their SE obtained from the fits in $\boldsymbol{B}$. In depressing the contractions elicited by either motor neuron, FRFamide $E$ was significantly less potent than FRFamides $C$ and $D\left({ }^{*} p<0.05\right.$, one-way ANOVA with post hoc pairwise comparisons using the Holm-Sidak method). (1, Effect of application of $1 \mu \mathrm{m}$ FRFamide Con the compound EJPs elicited by motor neuron B15. Representative EJPs before (1) and after (2) the FRFamide application are expanded and superimposed (with aligned baselines) in $\mathbf{C}$.

resting potential and reduction of the compound EJPs, conversely, has been described and analyzed with other myomodulins (Orekhova et al., 2003), as well as with the FRFamides A-C (Cropper et al., 1994). These two signature patterns of action appear to reflect, respectively, presynaptic and postsynaptic mechanisms of modulatory action at the ARC neuromuscular junction.

In the presynaptic mechanism, the modulatory peptide reduces the release of ACh from the ARC motor neurons and so reduces the opening of cationic $\mathrm{ACh}$-gated ion channels in the muscle membrane through which $\mathrm{Ca}^{2+}$ enters to contribute to the contraction. However, the voltage waveform of the compound EJP does not alter much, except during its initial development, because at its peak it is clamped by the nonlinear $I-V$ characteristics of the muscle membrane (Vilim et al., 1994; Kozak et al., 1996). In the postsynaptic mechanism, conversely, the modulatory peptide activates a characteristic modulator-specific outward K current in the muscle membrane that hyperpolarizes the muscle fiber at rest as well as during the compound EJP, which then reduces the entry of $\mathrm{Ca}^{2+}$ through a different pathway, the voltageactivated L-type Ca channels of the muscle (Brezina et al., 1994a,b; Cropper et al., 1994).

In the intact ARC neuromuscular junction, the two mechanisms can be difficult to distinguish unambiguously and indeed may coexist (Orekhova et al., 2003). The postsynaptic mechanism can be readily examined in isolation, however, in dissociated muscle fibers in which the presynaptic neurons are absent (Brezina et al., 1994c). We therefore used single dissociated ARC muscle fibers to examine the postsynaptic actions of the FRFamides and FMRFamide. We voltage clamped the fibers and, as shown for one representative experiment in Figure $12 \mathrm{~A}$, repetitively applied slow voltage ramps to obtain quasi-steady-state $I-V$ relations. Figure $12 \mathrm{~B}$ shows the $I-V$ relations obtained in such experiments before and after application of the FRFamides C-E. All three FRFamides activated a large outward current, as did the FRFamides A and $\mathrm{B}$ in the previous work (Cropper et al., 1994) in which this current was identified as the modulator-activated $\mathrm{K}$ current. However, even at 10-fold higher concentration, FMRFamide activated a much smaller amplitude of the outward current (Fig. 12A,C). [Although in Figure 12, A and $C$, FMRFamide was applied on top of FRF, after the effect of the FRF had essentially desensitized (Cropper et al., 1994), the smaller amplitude of the FMRFamide-activated current was not attributable to this desensitization, because the opposite order of application of FMRFamide and FRF gave the same result.] Thus, although FMRFamide is much more potent than the FRFamides in depressing the motor neuron-elicited contractions of the muscle, it is much less potent in activating the postsynaptic contraction-depressing mechanism. Probably, therefore, FMRFamide does indeed depress the contractions by acting primarily presynaptically, whereas the FRFamides may act primarily postsynaptically.

\section{Discussion}

Here we analyzed actions of two classes of RFamide neuropeptides, FRFamides and FMRFamide, in the CNS as well as the periphery of the Aplysia feeding system. We found that the actions of the RFamides are not identical, but neither are they unrelated; rather, they are complementary. When exogenously applied, both types of RFamides make feeding motor programs more egestive and reduce feeding muscle contractions. At each site, the two RFamides act by different, complementary mechanisms. To understand to what extent these complementary mechanisms may be exercised when the RFamides are released endogenously, however, it is also necessary to know to what extent the release of the two RFamides is coupled (Brezina and 
Weiss, 1997). We examined this in a series of cloning and localization studies.

\section{Cloning and localization studies}

Peptides that are derived from the same gene and precursor protein, as well as peptides that are derived from different precursors but are expressed in the same neuron, are likely to be co-packaged in the same dense-core vesicles and coreleased (Sossin et al., 1989). Two different scenarios could therefore have resulted in obligatorily corelease of the FRFamides and FMRFamide.

First, one gene could have encoded both FRFamides and FMRFamide. The Aplysia FMRFamide gene was already cloned, and it did not predict any FRFamide-like sequences. Given that alternative splicing of the FMRFamide gene was observed in Lymnaea (Santama and Benjamin, 2000), we sought to determine whether this also occurs in Aplysia. We found no evidence of such splicing. The cDNA encoding the FRFamide precursor was not yet identified. We cloned and sequenced it and found that, in addition to the known FRFamides (A-C), it encodes FRFamides $\mathrm{D}$ and $\mathrm{E}$ but not FMRFamide. Thus, at the level of their genes and precursor proteins, the FRFamides and FMRFamide are separate.

Second, separate FRFamide and FMRFamide genes could have been expressed in the same neurons. To determine whether this was the case, we performed in situ hybridization and immunostaining studies. In the buccal ganglion, we found that FMRFamide is expressed in a few large neurons of the ventral motor neuron cluster, as reported previously (Lloyd et al., 1987b; Church and Lloyd, 1991; Ono and McCaman, 1992), but FRFamide is not. Both RFamides are expressed, however, in the S1 and S2 sensory neuron clusters. To determine the RFamide content of individual sensory neurons, we used radiolabeling and HPLC purification and MALDI mass spectroscopy. The results confirmed immunocytochemical results and indicated that, although there are some S-cluster neurons that express both RFamides, most neurons express one type of peptide or the other. These studies confirmed moreover that all five FRFamides are indeed synthesized and cleaved from the precursor protein. Thus, the primarily separate expression of the FRFamides and FMRFamide suggested that, in principle, the two types of peptides could be released independently and exert physiological actions in varying combinations.

\section{Central actions of the RFamides}

When we examined actions of the FRFamides and FMRFamide on motor programs, we found that the two RFamides had distinct effects that combined in a complementary way. We elicited ingestive programs and found that exogenous application of both types of peptides made programs less ingestive. However, FRFamide decreased the $\mathrm{B} 8$ frequency in retraction, whereas FMRFamide increased the $\mathrm{B} 8$ frequency in protraction. Only when both RFamides were applied together did programs become fully egestive.

This type of change in motor output represents a change in the state of the feeding CPG because input activation (CBI-2 stimu- lation) remained the same (Proekt et al., 2004, 2007, 2008). A similar change has been observed after stimulation of the esophageal nerve (Proekt et al., 2004, 2007, 2008). Here we demonstrate that the esophageal nerve contains both the FRFamides and FMRFamide. The RFamides may thus participate in establishing an egestive state of the feeding CPG, perhaps in conjunction with other peptides such as Aplysia NPY (Jing et al., 2007).

\section{Peripheral actions of the RFamides}

Peripherally, we examined effects of exogenously applied FRFamides and FMRFamide on the ARC, a feeding muscle that has been studied extensively (Cohen et al., 1978; Weiss et al., 1978, 1979; Lloyd et al., 1987b; Cropper et al., 1987a,b, 1988; Brezina et al., 1994a,b,c; Vilim et al., 1996a,b, 2000). The newly identified FRFamides, D and E, like A-C (Cropper et al., 1994), depressed muscle contractions. So did FMRFamide; however, examination of the effects of the two types of RFamides on motor neuron-evoked EJPs suggested that, again, the FRFamides and FMRFamide depress contractions by distinct, complementary mechanisms. The FRFamides may act primarily postsynaptically, by activating a hyperpolarizing $\mathrm{K}$ current in the muscle itself, whereas FMRFamide may acts primarily presynaptically, by reducing the release of ACh from motor neuron terminals.

\section{Peripheral release and source of the RFamides}

Supporting the likely physiological relevance of the RFamide actions on the ARC muscle, electrical stimulation of its innervating nerve released endogenous RFamides. Presumably, both types of RFamides were released. Biochemically identified FRFamides (Cropper et al., 1994) as well as FMRFamide (Fig. 9) are present in the muscle. However, our in situ hybridization and immuno- 
staining results, together with previous biochemical work (Church and Lloyd, 1991), strongly suggest that the RFamides in the muscle do not derive from the motor neurons of the muscle. Rather, they appear to be contained in a distinct set of neuronal processes (Fig. 8). We suggest that these are the processes of $\mathrm{S}$-cluster sensory neurons. There is previous evidence for such innervation: backfills of the ARC muscle retrogradely label not only B15 and B16 but also S-cluster neurons (Vilim et al., 1996a). Mechanical or electrical stimulation of buccal muscles, including the ARC, activates S-cluster neurons (Fiore and Geppetti, 1981). This scenario implies that the RFamides are transported from the central somata of the S-cluster neurons to the periphery, although sensory information presumably flows in the opposite direction. There is ample precedent for this in other systems: mammalian dorsal root ganglion neurons, for example, release neuropeptides in the periphery, in which they then exert biological actions (Strand, 1999; Willis, 1999).

RFamide release, in contrast to neuropeptide release from motor neurons B15 and B16, was partly or almost completely eliminated when muscle contractions were blocked by hexamethonium. Our interpretation is that part of the RFamide release from sensory neuron terminals is elicited locally as those terminals detect muscle contractions. Consistent with this notion, S-cluster neurons appear to be mechanosensitive (Fiore and Geppetti, 1981; Walters et al., 2004). However, the buccal sensory neurons may not be the sole source of RFamides that act on the muscle. We cannot exclude the possibility that RFamides released by other neurons, or carried by the animal's blood, have effects on this system.

\section{Summary and implications}

The number and diversity of neuropeptides has stimulated investigators to search for rules linking aspects of this diversity to function. Here we studied two families of peptides that are structurally related but derive from different precursors expressed primarily in different neurons. We found that these facts are reflected in the actions of the peptides: the two peptide families act through different mechanisms that, nevertheless, complement each other so as to constitute parts of a coherent overall modulation of the system.

To further understand the functional logic of the modulation by the RFamides, it is instructive to compare their actions with those of other families of neuropeptides that modulate the Aplysia feeding system, in particular the myomodulins (Cropper et al., 1987b, 1988, 1991; Miller et al., 1993b; Vilim et al., 2000; Orekhova et al., 2003). As with the FRFamides, there are seven myomodulins encoded on the principal myomodulin gene that are probably all coreleased and exert similar actions, well represented by those of the predominant myomodulin (A) (Miller et al., 1993b). On the ARC, myomodulin A exerts both presynaptic and postsynaptic actions to depress muscle contractions (Cropper et al., 1987b, 1988, 1991; Orekhova et al., 2003). Thus, the actions that we found to be divided between the FRFamides and FMRFamide are combined in the myomodulins. Moreover, the myomodulins are intrinsic modulators: they are released from motor neuron B16 itself. In contrast, both the FRFamides and FMRFamide are extrinsic modulators, released from neurons that do not directly mediate behavior. Consequently, the different components of the modulation by the myomodulins are coupled in a relatively fixed manner to each other and to the basic motor neuron drive to the system (Brezina and Weiss, 1997). In contrast, the modulation by the FRFamides and FMRFamide can in principle be adjusted, according to behavioral demands, independently of this drive and indeed, because the
FRFamides and FMRFamides originate from different neurons, independently of each other. The responsiveness of the RFamide release to the contraction of the muscle is interesting in this respect. We speculate that, whereas the modulation by the myomodulins reflects the motor commands to the muscle, the modulation by the RFamides reflects feedback about how those commands have been expressed. Future work will determine whether the sensory neurons that release the FRFamides and FMRFamide respond, as this scenario might suggest, to different types of mechanical stimuli.

RFamides are present in many other invertebrates and vertebrates (Price and Greenberg, 1977; Greenberg and Price, 1992; Dockray, 2004; Bechtold and Luckman, 2007; Li and Kim, 2008). As in Aplysia, multiple forms of RFamides, derived from different precursors, are often present and exert a multitude of actions. However, little is known about joint actions of these peptides, and this issue is generally discussed in terms of peptide redundancy or functional divergence. The RFamides thus present a good opportunity to examine more generally the extent to which structurally related neuropeptides exert functionally related actions.

\section{References}

Baxter DA, Byrne JH (2006) Feeding behavior of Aplysia: a model system for comparing cellular mechanisms of classical and operant conditioning. Learn Mem 13:669-680.

Bechtold DA, Luckman SM (2007) The role of RFamide peptides in feeding. J Endocrinol 192:3-15.

Brezina V (1994) A simple technique for on-line measurement of contractions of single smooth muscle fibers under current or voltage clamp. Pflugers Arch 429:126-133.

Brezina V, Weiss KR (1997) Analyzing the functional consequences of transmitter complexity. Trends Neurosci 20:538-543.

Brezina V, Evans CG, Weiss KR (1994a) Characterization of the membrane ion currents of a model molluscan muscle, the accessory radula closer muscle of Aplysia california. I. Hyperpolarization-activated currents. J Neurophysiol 71:2093-2112.

Brezina V, Evans CG, Weiss KR (1994b) Characterization of the membrane ion currents of a model molluscan muscle, the accessory radula closer muscle of Aplysia californica. II. Depolarization-activated K currents. J Neurophysiol 71:2113-2125.

Brezina V, Evans CG, Weiss KR (1994c) Characterization of the membrane ion currents of a model molluscan muscle, the accessory radula closer muscle of Aplysia californica. III. Depolarization-activated Ca current. J Neurophysiol 71:2126-2138.

Brezina V, Orekhova IV, Weiss KR (1996) Functional uncoupling of linked neurotransmitter effects by combinatorial convergence. Science 273:806-810.

Chomczynski P, Sacchi N (1987) Single-step method of RNA isolation by acid guanidinium thiocyanate-phenol-chloroform extraction. Anal Biochem 162:156-159.

Church PJ, Lloyd PE (1991) Expression of diverse neuropeptide cotransmitters by identified motor neurons in Aplysia. J Neurosci 11:618-625.

Cohen JL, Weiss KR, Kupfermann I (1978) Motor control of buccal muscles in Aplysia. J Neurophysiol 41:157-180.

Cropper EC, Lloyd PE, Reed W, Tenenbaum R, Kupfermann I, Weiss KR (1987a) Multiple neuropeptides in cholinergic motor neurons of Aplysia: evidence for modulation intrinsic to the motor circuit. Proc Natl Acad Sci U S A 84:3486-3490.

Cropper EC, Tenenbaum R, Kolks MA, Kupfermann I, Weiss KR (1987b) Myomodulin: a bioactive neuropeptide present in an identified cholinergic buccal motor neuron of Aplysia. Proc Natl Acad Sci U S A 84:5483-5486.

Cropper EC, Miller MW, Tenenbaum R, Kolks MA, Kupfermann I, Weiss KR (1988) Structure and action of buccalin: a modulatory neuropeptide localized to an identified small cardioactive peptide-containing cholinergic motor neuron of Aplysia californica. Proc Natl Acad Sci USA 85:6177-6181.

Cropper EC, Miller MW, Vilim FS, Tenenbaum R, Kupfermann I, Weiss KR 
(1990) Buccalin is present in the cholinergic motor neuron B16 of Aplysia and it depresses accessory radula closer muscle contractions evoked by stimulation of B16. Brain Res 512:175-179.

Cropper EC, Vilim FS, Alevizos A, Tenenbaum R, Kolks MA, Rosen S, Kupfermann I, Weiss KR (1991) Structure, bioactivity, and cellular localization of myomodulin B: a novel Aplysia peptide. Peptides 12: 683-690.

Cropper EC, Brezina V, Vilim FS, Harish O, Price DA, Rosen S, Kupfermann I, Weiss KR (1994) FRF peptides in the ARC neuromuscular system of Aplysia: purification and physiological actions. J Neurophysiol 72: 2181-2195.

Cropper EC, Evans CG, Hurwitz I, Jing J, Proekt A, Romero A, Rosen SC (2004) Feeding neural networks in the mollusc Aplysia. Neurosignals 13:70-86.

Dockray GJ (2004) The expanding family of -RFamide peptides and their effects on feeding behaviour. Exp Physiol 89:229-235.

Eberwine JH, Valentino KL, Barchas JD (1994) In situ hybridization in neurobiology: advances in methodology. New York: Oxford UP.

Fiore L, Geppetti L (1981) Neural control of buccal mass activity in Aplysia. In: Neurobiology of invertebrates (Salánki J, ed), pp 201-223. Oxford: Pergamon.

Fiore L, Meunier JM (1975) A network of synaptic relations in the buccal ganglia of Aplysia. Brain Res 92:336-340.

Fujisawa Y, Furukawa Y, Ohta S, Ellis TA, Dembrow NC, Li L, Floyd PD, Sweedler JV, Minakata H, Nakamaru K, Morishita F, Matsushima O, Weiss KR, Vilim FS (1999) The Aplysia mytilus inhibitory peptiderelated peptides: identification, cloning, processing, distribution, and action. J Neurosci 19:9618-9634.

Furukawa Y, Nakamaru K, Wakayama H, Fujisawa Y, Minakata H, Ohta S, Morishita F, Matsushima O, Li L, Romanova E, Sweedler JV, Park JH, Romero A, Cropper EC, Dembrow NC, Jing J, Weiss KR, Vilim FS (2001) The enterins: a novel family of neuropeptides isolated from the enteric nervous system and CNS of Aplysia. J Neurosci 21:8247-8261.

Greenberg MJ, Price DA (1992) Relationships among the FMRFamide-like peptides. Prog Brain Res 92:25-37.

Hoek RM, Li KW, van Minnen J, Lodder JC, de Jong-Brink M, Smit AB, van Kesteren RE (2005) LFRFamides: a novel family of parasitationinduced -RFamide neuropeptides that inhibit the activity of neuroendocrine cells in Lymnaea stagnalis. J Neurochem 92:1073-1080.

Hurwitz I, Susswein AJ (1996) B64, a newly identified central pattern generator element producing a phase switch from protraction to retraction in buccal motor programs of Aplysia californica. J Neurophysiol 75: $1327-1344$.

Hurwitz I, Neustadter D, Morton DW, Chiel HJ, Susswein AJ (1996) Activity patterns of the B31/B32 pattern initiators innervating the I2 muscle of the buccal mass during normal feeding movements in Aplysia californica. J Neurophysiol 75:1309-1326.

Hurwitz I, Kupfermann I, Susswein AJ (1997) Different roles of neurons B63 and B34 that are active during the protraction phase of buccal motor programs in Aplysia californica. J Neurophysiol 78:1305-1319.

Jing J, Weiss KR (2001) Neural mechanisms of motor program switching in Aplysia. J Neurosci 21:7349-7362.

Jing J, Weiss KR (2002) Interneuronal basis of the generation of related but distinct motor programs in Aplysia: implications for current neuronal models of vertebrate intralimb coordination. J Neurosci 22:6228-6238.

Jing J, Weiss KR (2005) Generation of variants of a motor act in a modular and hierarchical motor network. Curr Biol 15:1712-1721.

Jing J, Vilim FS, Horn CC, Alexeeva V, Hatcher NG, Sasaki K, Yashina I, Zhurov Y, Kupfermann I, Sweedler JV, Weiss KR (2007) From hunger to satiety: reconfiguration of a feeding network by Aplysia neuropeptide Y. J Neurosci 27:3490-3502.

Koh HY, Vilim FS, Jing J, Weiss KR (2003) Two neuropeptides colocalized in a command-like neuron use distinct mechanisms to enhance its fast synaptic connection. J Neurophysiol 90:2074-2079.

Kozak JA, Weiss KR, Brezina V (1996) Two ion currents activated by acetylcholine in the ARC muscle of Aplysia. J Neurophysiol 75:660-677.

Kupfermann I (1991) Functional studies of cotransmission. Physiol Rev 71:683-732.

Lechner HA, Baxter DA, Byrne JH (2000) Classical conditioning of feeding in Aplysia. II. Neurophysiological correlates. J Neurosci 20:3377-3386.

Li C, Kim K (2008) Neuropeptides. (Sept. 25, 2008), WormBook, ed. The
C. elegans Research Community, WormBook, doi/10.1895/wormbook.1.142. 1, http://www.wormbook.org.

Li L, Moroz TP, Garden RW, Floyd PD, Weiss KR, Sweedler JV (1998) Mass spectrometric survey of interganglionically transported peptides in Aplysia. Peptides 19:1425-1433.

Li L, Romanova EV, Rubakhin SS, Alexeeva V, Weiss KR, Vilim FS, Sweedler JV (2000) Peptide profiling of cells with multiple gene products: combining immunochemistry and MALDI mass spectrometry with on-plate microextraction. Anal Chem 72:3867-3874.

Li L, Floyd PD, Rubakhin SS, Romanova EV, Jing J, Alexeeva VY, Dembrow NC, Weiss KR, Vilim FS, Sweedler JV (2001) Cerebrin prohormone processing, distribution and action in Aplysia californica. J Neurochem 77:1569-1580.

Lloyd PE, Kupfermann I, Weiss KR (1987a) Sequence of small cardioactive peptide A: a second member of a class of neuropeptides in Aplysia. Peptides 8:179-184.

Lloyd PE, Frankfurt M, Stevens P, Kupfermann I, Weiss KR (1987b) Biochemical and immunocytological localization of the neuropeptides FMRFamide, SCPA, SCPB, to neurons involved in the regulation of feeding in Aplysia. J Neurosci 7:1123-1132.

Mahon AC, Lloyd PE, Weiss KR, Kupfermann I, Scheller RH (1985) The small cardioactive peptides A and B of Aplysia are derived from a common precursor molecule. Proc Natl Acad Sci U S A 82:3925-3929.

Marder E, Christie AE, Kilman VL (1995) Functional organization of cotransmission systems: lessons from small nervous systems. Invert Neurosci 1:105-112.

Miller MW, Beushausen S, Cropper EC, Eisinger K, Stamm S, Vilim FS, Vitek A, Zajc A, Kupfermann I, Brosius J, et al. (1993a) The buccalin-related neuropeptides: isolation and characterization of an Aplysia cDNA clone encoding a family of peptide cotransmitters. J Neurosci 13:3346-3357.

Miller MW, Beushausen S, Vitek A, Stamm S, Kupfermann I, Brosius J, Weiss KR (1993b) The myomodulin-related neuropeptides: characterization of a gene encoding a family of peptide cotransmitters in Aplysia. J Neurosci 13:3358-3367.

Morgan PT, Perrins R, Lloyd PE, Weiss KR (2000) Intrinsic and extrinsic modulation of a single central pattern generating circuit. J Neurophysiol 84:1186-1193.

Morgan PT, Jing J, Vilim FS, Weiss KR (2002) Interneuronal and peptidergic control of motor pattern switching in Aplysia. J Neurophysiol 87:49-61.

Morton DW, Chiel HJ (1993a) In vivo buccal nerve activity that distinguishes ingestion from rejection can be used to predict behavioral transitions in Aplysia. J Comp Physiol A 172:17-32.

Morton DW, Chiel HJ (1993b) The timing of activity in motor neurons that produce radula movements distinguishes ingestion from rejection in Aplysia. J Comp Physiol A 173:519-536.

Nargeot R, Baxter DA, Byrne JH (1999) In vitro analog of operant conditioning in Aplysia. I. Contingent reinforcement modifies the functional dynamics of an identified neuron. J Neurosci 19:2247-2260.

Nielsen H, Engelbrecht J, Brunak S, von Heijne G (1997) Identification of prokaryotic and eukaryotic signal peptides and prediction of their cleavage sites. Protein Eng 10:1-6.

Nusbaum MP, Blitz DM, Swensen AM, Wood D, Marder E (2001) The roles of co-transmission in neural network modulation. Trends Neurosci 24:146-154.

Ono JK, McCaman RE (1992) In situ hybridization of whole-mounts of Aplysia ganglia using non-radioactive probes. J Neurosci Methods 44:71-79.

Orekhova IV, Alexeeva V, Church PJ, Weiss KR, Brezina V (2003) Multiple presynaptic and postsynaptic sites of inhibitory modulation by myomodulin at ARC neuromuscular junctions of Aplysia. J Neurophysiol 89:1488-1502.

Price DA, Greenberg MJ (1977) Structure of a molluscan cardioexcitatory neuropeptide. Science 197:670-671.

Proekt A, Weiss KR (2003) Convergent mechanisms mediate preparatory states and repetition priming in the feeding network of Aplysia. J Neurosci 23:4029-4033.

Proekt A, Brezina V, Weiss KR (2004) Dynamical basis of intentions and expectations in a simple neuronal network. Proc Natl Acad Sci U S A 101:9447-9452.

Proekt A, Vilim FS, Alexeeva V, Brezina V, Friedman A, Jing J, Li L, Zhurov Y, Sweedler JV, Weiss KR (2005) Identification of a new neuropeptide pre- 
cursor reveals a novel source of extrinsic modulation in the feeding system of Aplysia. J Neurosci 25:9637-9648.

Proekt A, Jing J, Weiss KR (2007) Multiple contributions of an inputrepresenting neuron to the dynamics of the Aplysia feeding network. J Neurophysiol 97:3046-3056.

Proekt A, Wong J, Zhurov Y, Kozlova N, Weiss KR, Brezina V (2008) Predicting adaptive behavior in the environment from central nervous system dynamics. PLoS ONE 3:e3678.

Romanova EV, Fosser KA, Rubakhin SS, Nuzzo RG, Sweedler JV (2004) Engineering the morphology and electrophysiological parameters of cultured neurons by microfluidic surface patterning. FASEB J 18:1267-1269.

Rosen SC, Teyke T, Miller MW, Weiss KR, Kupfermann I (1991) Identification and characterization of cerebral-to-buccal interneurons implicated in the control of motor programs associated with feeding in Aplysia. J Neurosci 11:3630-3655.

Rubakhin SS, Sweedler JV (2007) Characterizing peptides in individual mammalian cells using mass spectrometry. Nat Protoc 2:1987-1997.

Sambrook J, Fritsch EF, Maniatis T (1989) Molecular cloning: a laboratory manual. New York: Cold Spring Harbor Laboratory.

Santama N, Benjamin PR (2000) Gene expression and function of FMRFamide-related neuropeptides in the snail Lymnaea. Microsc Res Tech 49:547-556.

Sasaki K, Due MR, Jing J, Weiss KR (2007) Feeding CPG in Aplysia directly controls two distinct outputs of a compartmentalized interneuron that functions as a CPG element. J Neurophysiol 98:3796-3801.

Sasaki K, Jing J, Due MR, Weiss KR (2008) An input-representing interneuron regulates spike timing and thereby phase switching in a motor network. J Neurosci 28:1916-1928.

Schaefer M, Picciotto MR, Kreiner T, Kaldany RR, Taussig R, Scheller RH (1985) Aplysia neurons express a gene encoding multiple FMRFamide neuropeptides. Cell 41:457-467.

Seidah NG, Chrétien M (1999) Proprotein and prohormone convertases: a family of subtilases generating diverse bioactive polypeptides. Brain Res 848:45-62.

Sossin WS, Fisher JM, Scheller RH (1989) Cellular and molecular biology of neuropeptide processing and packaging. Neuron 2:1407-1417.

Strand FL (1999) Neuropeptides: regulators of physiological processes. Cambridge, MA: MIT.

Susswein AJ, Byrne JH (1988) Identification and characterization of neurons initiating patterned neural activity in the buccal ganglia of Aplysia. J Neurosci 8:2049-2061.
Sweedler JV, Li L, Rubakhin SS, Alexeeva V, Dembrow NC, Dowling O, Jing J, Weiss KR, Vilim FS (2002) Identification and characterization of the feeding circuit-activating peptides, a novel neuropeptide family of Aplysia. J Neurosci 22:7797-7808.

Vilim FS, Cropper EC, Rosen SC, Tenenbaum R, Kupfermann I, Weiss KR (1994) Structure, localization, and action of buccalin B: a bioactive peptide from Aplysia. Peptides 15:959-969.

Vilim FS, Price DA, Lesser W, Kupfermann I, Weiss KR (1996a) Costorage and corelease of modulatory peptide cotransmitters with partially antagonistic actions on the accessory radula closer muscle of Aplysia californica. J Neurosci 16:8092-8104.

Vilim FS, Cropper EC, Price DA, Kupfermann I, Weiss KR (1996b) Release of peptide cotransmitters in Aplysia: regulation and functional implications. J Neurosci 16:8105-8114.

Vilim FS, Cropper EC, Price DA, Kupfermann I, Weiss KR (2000) Peptide cotransmitter release from motorneuron B16 in Aplysia californica: costorage, corelease, and functional implications. J Neurosci 20:2036-2042.

Vilim FS, Alexeeva V, Moroz LL, Li L, Moroz TP, Sweedler JV, Weiss KR (2001) Cloning, expression and processing of the CP2 neuropeptide precursor of Aplysia. Peptides 22:2027-2038.

Walters ET, Bodnarova M, Billy AJ, Dulin MF, Díaz-Ríos M, Miller MW, Moroz LL (2004) Somatotopic organization and functional properties of mechanosensory neurons expressing sensorin-A mRNA in Aplysia californica. J Comp Neurol 471:219-240.

Warman EN, Chiel HJ (1995) A new technique for chronic single-unit extracellular recording in freely behaving animals using pipette electrodes. J Neurosci Methods 57:161-169.

Weiss KR, Cohen JL, Kupfermann I (1978) Modulatory control of buccal musculature by a serotonergic neuron (metacerebral cell) in Aplysia. J Neurophysiol 41:181-203.

Weiss KR, Mandelbaum DE, Schonberg M, Kupfermann I (1979) Modulation of buccal muscle contractility by serotonergic metacerebral cells in Aplysia: evidence for a role of cyclic adenosine monophosphate. J Neurophysiol 42:791-803.

Willis WD Jr (1999) Dorsal root potentials and dorsal root reflexes: a double-edged sword. Exp Brain Res 124:395-421.

Wu JS, Due MR, Sasaki K, Proekt A, Jing J, Weiss KR (2007) State dependence of spike timing and neuronal function in a motor pattern generating network. J Neurosci 27:10818-10831. 